\title{
Behavior of Bromophthalein Magenta E (Tetrabromophe- nolphthalein Ethyl Ester) With Organic Bases and Its Bearing on the Brønsted-Lowry and Lewis Concepts of Acidity
}

\author{
Marion Maclean Davis and Hannah B. Hetzer
}

\begin{abstract}
In a continuation of spectrophotometric studies of its indicator properties in benzene, bromophthalein magenta $\mathrm{E}$ (tetrabromophenolphthalein ethyl ester) has been shown to react with 1,3-diphenylguanidine and with 1,2,3-triphenylguanidine in two steps that correspond to the equations: (1) $\mathrm{R}_{3} \mathrm{~N}+\mathrm{HX} \rightleftarrows \mathrm{R}_{3} \mathrm{NH}^{+} \ldots \mathrm{X}^{-}$(magenta); (2) $\mathrm{R}_{3} \mathrm{NH}^{+} \ldots \mathrm{X}^{-}$ $+\mathrm{R}_{3} \mathrm{~N} \rightleftarrows\left(\mathrm{R}_{3} \mathrm{NHNR}\right)^{+} \mathrm{X}^{-}$(blue). The association constants $K_{1}$ and $K_{2}$ for these reactions with diphenylguanidine are $2.2 \times 10^{5}$ and 15.5 , respectively. For the reactions with triphenylguanidine, $K_{1}$ is 525 and $K_{2}$ is of the same order as the $K_{2}$ for the reaction with diphenylguanidine. Replacing benzene by ethanol or pyridine produces the same kind of effect as increasing the concentration of di- or triphenylguanidine. The results indicate that the Brønsted-Lowry formulation of an acid-base reaction should be modified, and that hydrogen acids should be regarded as a special class of Lewis acids.
\end{abstract}

\section{Introduction}

In connection with a project at this Bureau to develop methods for measuring acidity and basicity in organic solvents, the utility of indicator dyes has received special consideration. Indicator dyes, if available, would be particularly useful for solutions of acids and bases in inert solvents like benzene, because such solutions do not contain significant quantities of free hydrogen ions, and measurements by means of the hydrogen or glass electrodes are therefore not applicable. In a previous paper $[1],{ }^{2}$ the preparation of the acidic indicator dye, bromophthalein magenta $\mathrm{E}$ (the ethyl ester of tetrabromophenolphthalein), was described and a comprehensive survey of its reactions with organic bases in benzene and some other organic solvents was presented. A quartz photoelectric spectrophotometer was used in following the course of the reactions. This paper deals with a continuation of such studies, which are a prerequisite to practical applications of the indicator.

Apart from the bearing of the results on qualitative and quantitative applications of bromophthalein magenta $\mathrm{E}$, the latest measurements are of importance in clarifying the conflict between the BrønstedLowry and Lewis concepts of acidity. As is well known, Brønsted and Lowry formulated an acid-base reaction as the transfer of a proton from one base to another $[2$ to 5], and Lewis formulated it as the addition of an acid to a base [6 to 8]. Compounds that can donate a proton, which are the only substances recognized as acids by Brønsted and Lowry, form a homogeneous group for which valuable quantitative interrelationships have been derived.

1 Presented in part at the 119th meeting of the American Chemical Society at Cleveland, Ohio, A pril 1951. The authors wish to acknowledge a grant from Cleveland, Ohio, April 1951. The authors wish to ackn
the Office of Naval Research, which facilitated the work.

Figures in brackets indicate the literature references at the end of this pape
This has not yet proved true for Lewis acids, which include such diverse substances as silver ion, iodine, and sulfur dioxide. However, the Lewis theory has the merit of correlating a much wider range of chemical phenomena in a qualitative sense. Thus, two different but useful concepts of acidity have coexisted, in much the same way as the wave and corpuscular theories of light.

Over 40 years ago Lewis said, "... We are beginning to realize that the phenomena of aqueous solutions are but special instances of the widely varying phenomena occurring in other solvents; and it seems unlikely that a satisfactory understanding of the behavior of aqueous solutions can come except through a careful study of nonaqueous solutions ..." [9]. Two decades later Brønsted wrote, "The properties of acids and bases may then by no means, as is generally believed, be investigated in aqueous solutions but must on the contrary be investigated in solutions of benzene-like, aprotic character if we would gain the most comprehensive and the deepest insight into the nature of these substances" [5]. Within the past half-century systematic investigations have been made of acid-base systems in nonaqueous solvents such as liquid ammonia, liquid sulfur dioxide, and glacial acetic acid, but apart from a few exploratory studies, outstanding among which are those by LaMer and Downes $[10,11]$, investigations in aprotic solvents have been neglected. Even Brønsted left the systematic study of acid-base behavior in inert solvents to later investigators, except for one paper that dealt briefly with relative acidic strengths in benzene and included no experimental data [12]. This neglect is understandable because of the unavailability of suitable indicator acids and bases. The lack of indicators still exists, as pointed out by Kolthoff, who recently wrote, "With the extension of acid-base titrations to organic 
solvents the need for more acid-base indicators is growing. The titration of Lewis acids in aprotonic solvents is still awaiting systematic research on equilibrium constants between these acids and various bases. Such studies include the search for suitable indicators and their equilibrium constants in given systems" [13]. This need will probably not be met completely until a number of new indicators have been synthesized that have adequate solubility in the solvents concerned, as well as adequate sensitivity and stability. However, various dyes that are described in the literature or known to dye manufacturers would probably prove very useful if made available to investigators. For example, the compound termed by us "bromophthalein magenta E" has been known since 1897 [14], although its potential use as an indicator of basicity in inert solvents was not known until a systematic search at this $\mathrm{Bu}-$ reau for suitable indicators disclosed its valuable properties [1].

Before proceeding to a discussion of our latest studies, it is well to review briefly some of our earlier observations. With regard to bromophthalein magenta E, it is a brick-red solid that dissolves readily in benzene and other inert solvents to give a yellow solution. It is a monobasic acid and is monomeric in solution; these properties result in greatly simplified behavior of the indicator as compared with the sulfonephthalein indicators, which are dibasic acids, and with carboxylic acids, which are partly dimerized in solution. An instantaneous reaction occurs between bromophthalein magenta $\mathrm{E}$ and an aliphatic amine in an inert solvent, as shown by a vivid change in color. In contrast to the behavior of an acidic indicator with bases in aqueous solutions, the color produced is not the same for all bases. Thus, with a primary amine such as benzylamine it is red-purple, with a secondary amine such as piperidine it is purpleblue ("cornflower" blue), and with a tertiary amine such as triethylamine it is magenta. A magenta color is also produced by 1,3-diphenyl-, 1,3-di-otolyl-, and 1,2,3-triphenylguanidine and by various other bases such as hexamethylenetetramine. A solution of a quaternary ammonium salt of bromophthalein magenta $\mathrm{E}$ in an inert solvent is blue, without a purple tinge. An explanation of this differentiating behavior of bromophthalein magenta $\mathrm{E}$ toward different classes of bases was presented in the reference cited [1].

For the moment, let us focus attention on the reaction that produces a magenta color. This reaction may be formulated quite simply as the combination of one molecule of the indicator $(A)$ with one molecule of the base $(B)$ to give a molecule of a salt that will be referred to in this paper as the primary salt $\left(S_{1}\right)$. In the examples studied, the reaction did not proceed to completion, but produced an equilibrium mixture of $A, B$, and $S_{1}$. It therefore offered a means of determining the relative strengths of bases in terms of association constants. That is,

$$
K_{\text {assn }}=\frac{\left[S_{1}\right]}{[A][B]} .
$$

Provisional values of the association constant were given previously for triethylamine, diphenylguanidine, and di-o-tolylguanidine [1]. It was desirable to check some of these measurements with better control of the temperature than was feasible formerly and at additional concentrations made possible by the acquisition of shorter absorption cells. This paper is concerned with measurements of the reaction of bromophthalein magenta $\mathrm{E}$ with triphenylguanidine in benzene and an extension of the earlier measurements with diphenylguanidine, as well as effects produced by adding ethanol or pyridine. As will be shown, these measurements have demonstrated that salt formation between bromophthalein magenta and a base such as diphenylguanidine occurs in two steps, yielding products that we shall term the primary salt $\left(S_{1}\right)$ and the secondary salt $\left(S_{2}\right)$. The first step would be obscured in an active solvent such as water. The theoretical significance of these results will be discussed.

A few words should be said about the character of benzene as a solvent. Although classed as an inert or "aprotic" solvent, it is known to exhibit basic properties in some instances. A full discussion of the subject is outside the scope of this paper, but a few examples may be cited here. For instance, O'Brien, Kenny, and Zuercher obtained evidence of hydrogen bonding between benzene and hydrogen chloride and gave a provisional value of 0.16 (in terms of molalities) for the association constant; by comparison, a value of $1.23 \times 10^{6}$ was given for the association constant when hydrogen chloride combines with water [15]. Staveley, Jeffes and Moy discussed evidence from solubility measurements that benzene can sometimes associate with other molecules that contain a hydrogen atom capable of forming a bridge (for example, water), and suggested that the hydrogen atom of the donor molecule may be attracted toward the center of the benzene ring in a direction normal to the plane of the ring [16]. Recently, Benesi and Hildebrand have obtained interesting evidence of $1: 1$ combination of benzene and iodine in carbon tetrachloride, with the association constant 1.72 [17]. Mulliken has discussed various possible structures of the complex of iodine and benzene, the most probable of which he considers to be a structure in which the iodine molecule lies above the plane of the benzene ring, with its axis parallel to the plane of the ring [18]. As to possible acidic properties of benzene, Rao and Jatkar concluded that one or two of the hydrogens in benzene may participate in hydrogen bridge formation, for example, to chlorine atoms of chloroform, methylene chloride, or carbon tetrachloride [19]. The available evidence may be summarized as indicating associative forces between benzene and many other types of molecules that account for its excellent solvent properties; in some cases, the associations may be likened to acid-base interactions. The associative forces are relatively very small as compared with those involved in the interaction of compounds familiarly known as acids and bases, such as the 
compounds with which this paper is concerned, although in some instances it may prove necessary to take them into account.

\section{Equipment and Procedure}

Spectrophotometric data were obtained with a Beckman Model DU quartz photoelectric spectrophotometer. The absorption cells, which were all provided with glass stoppers, were assembled from endplates and spacers constructed in the optical shop of this Bureau. For 1-cm cells, both endplates were of crystalline quartz, $2 \mathrm{~mm}$ in thickness, and the spacer was made of fused quartz. For shorter cells, one of the $2-\mathrm{mm}$ endplates was replaced by the tubulated fused-quartz endplate previously described [1]. The spacers used for 1-, 2.5-, and 5-mm cells were made of stainless steel. The shortest cells were made by combining a tubulated endplate with an endplate of crystalline quartz, $3 \mathrm{~mm}$ in thickness, having a central indented area $0.1 \mathrm{~mm}$ or $0.5 \mathrm{~mm}$ in depth. The cells were placed in a thermostated box maintained at $25.0^{\circ} \pm 0.1^{\circ} \mathrm{C}[20]$ half an hour or more before measurements were begun. The temperature of the room was automatically controlled to stay between $24^{\circ}$ and $27^{\circ} \mathrm{C}$ but was usually between $25^{\circ}$ and $26^{\circ} \mathrm{C}$.

The procedure followed in the preparation and dilution of solutions has already been described [1]. When the molar concentration of the base was twice that of the indicator or greater, the same amount of base was added to both cells. Otherwise, the reference cell contained only the pure solvent.

The following symbols and terminology are used. $C_{s}, C_{a}$, and $C_{b}=$ the initial concentration of the salt, acid, and base, respectively, in moles per liter; $[S]$, $[A]$, and $[B]=$ the molar concentration of the salt, acid, and base, respectively, in an equilibrium mixture; $S_{1}=$ the primary salt and $S_{2}=$ the secondary salt. $T_{s}$ (transmittancy of the solute) $=T_{\text {soln }} / T_{\text {solv }} ; A_{s}$ (absorbancy of the solute) $=-\log _{10} T_{s} ; a_{M}$ (molar absorbancy index $)=A_{s} /(b M)$, where $b=$ length in centimeters of the absorption cell, and $M=$ concentration of the solution in moles per liter.

\section{Materials}

Benzene, bromophthalein magenta E, 1,3-diphenylguanidine, and 1,2,3-triphenylguanidine were of the same quality and were purified in the same way as the materials described previously [1]. Commercial "absolute" ethanol was purified by the method of Lund and Bjerrum [21] immediately before use. A high grade of pyridine was dried over sodium hydroxide and distilled from fresh sodium hydroxide immediately before use. Separate fractions of the distillate were collected in a desiccator protected by a soda-lime tube; the middle fraction was used.

\section{Data and Discussion}

\section{The Primary Reaction}

As previously reported [1], the spectral absorbancy curve of BPM-E (bromophthalein magenta $\mathrm{E}$ ) in benzene shows a maximum near $405 \mathrm{~m} \mu$, with a molar absorbancy index of $26,200 .^{3}$

When diphenylquanidine is added in successive small increments to a solution of bromophthalein magenta $\mathrm{E}$ in benzene, the original yellow color of the indicator changes progressively through tones of orange and red to the magenta color that indicates formation of the primary salt. The primary salt shows maximum absorption near $540 \mathrm{~m} \mu$. The intermediate tones correspond to mixtures of unchanged indicator with the primary salt. Curves obtained for some of the solutions are shown in figure $1 .{ }^{4}$ Curve $\mathrm{A}$ is for bromophthalein magenta E $\left(2.5 \times 10^{-5}\right.$ $M, 5-\mathrm{mm}$ cell). Curves 1 to 5 are for its mixtures with $0.2,0.4,0.6,0.8$, and 1.0 molar equivalent, respectively, of diphenylguanidine. For the complete conversion of BPM-E to its magenta salt, an excess of diphenylguanidine was necessary. In the experiments under discussion, the absorbancy curve remained practically constant when the molar concentration of diphenylguanidine was from 25 to 70 times that of the indicator. At much higher concentrations of diphenylguanidine, the magenta color shifted toward blue, indicating a secondary reaction. The best "limiting curve" for the primary reaction was considered to be the one that had the lowest value of absorbancy at $405 \mathrm{~m} \mu$ and the highest value at $540 \mathrm{~m} \mu$. On this basis, the curve for a solution that contained $2.5 \times 10^{-5} M$ of BPM-E with 45 molar equivalents of diphenylguanidine was adopted as the curve for the primary salt, $S_{1}$; the molar absorbancy indexes for $405 \mathrm{~m} \mu$ and $540 \mathrm{~m} \mu$ are 2,200 and 40,800 , respectively. The curves in figure 1 show sharp isosbestic points near $355 \mathrm{~m} \mu$ and $455 \mathrm{~m} \mu .^{5}$

As bromophthalein magenta does not show measurable absorbancy at $540 \mathrm{~m} \mu$ under the conditions used, this is a very suitable wavelength for quantitative studies of the formation of the primary salt. The sensitivity of the absorbancy at $540 \mathrm{~m} \mu$ to small increments of diphenylguanidine is shown in figure 2

3 The molar absorbancy index was given earlier as 26,500; the newer value was calculated from the average of numerous measurements of transmittancy, which

differed by 0.1 or 0.2 percent.
4 To permit comparisons, values of the molar absorbancy index (which takes into account the length of the light path as well as the molar concentration) are plotted along the vertical axis in most of the figures. Strictly speaking, of course, the term "molar absorbancy index", does not apoly to mixtures of compounds, such as those in which bromophthalein magenta $\mathrm{E}$ has been partially transformed into a salt.

ransformed into a salt.

Diphenylguanidine has a strong absorption band in the ultraviolet region, but an approximately $0.01-M$ solution in benzene does not show measurable absorption at wavelengths longer than $400 \mathrm{~m} \mu$ with the cells used. Slight color is sometimes evident in more concentrated solutions, which may indicate a trace of some oxidation product of aniline. The spectral absorption of any such substance should be nullified by the addition of equal amounts of diphenyiguanidine to the "solution" cell and the reference cell. Absorption due to diphenylguanidine is probably shifted to shorter wavelengths when it is transformed into a salt. The effect of such a shift, which would be very small because of the low concentration of salt formed in any of the solutions, would not be detectable in the spectral region investigated. 


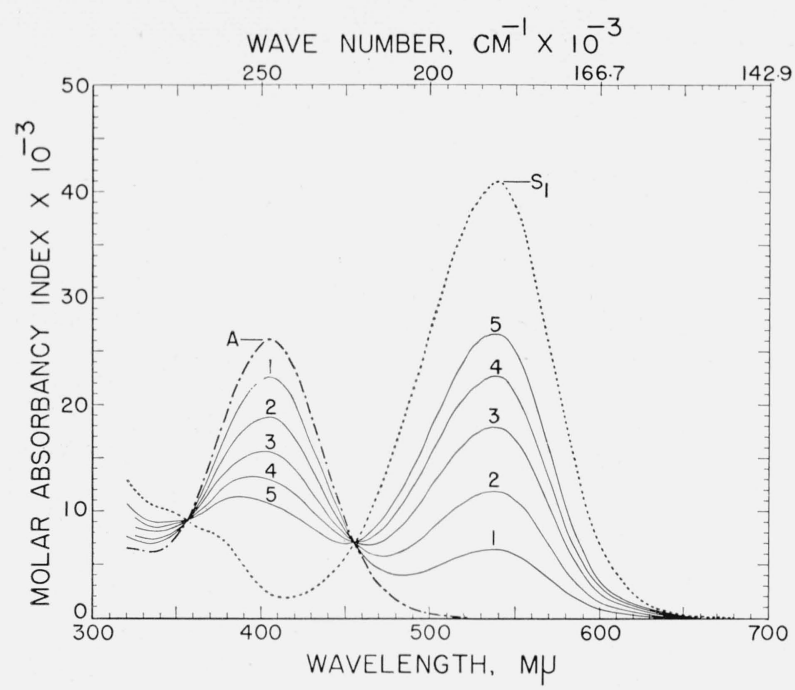

Figure 1. Changes in molar absorbancy accompanying the primary reaction of bromophthalein magenta $\mathrm{E}, 2.5 \times 10^{-5} \mathrm{M}$ in benzene, with diphenylguanidine.

A, BPM-E without added base; 1 to 5 , with $0.2,0.4,0.6,0.8$, and 1.0 molar equivalent of diphenylguanidine, respectively; $S_{1}$, with 45 molar equivalents of diphenylguanidine.

(curve I), in which the absorbancy at $540 \mathrm{~m} \mu$ is plotted against the concentration of the base, expressed as molar equivalents of the indicator. The successive changes in color are most evident for small increments of diphenylguanidine; a concentration at least as small as $5 \times 10^{-6} M$ can be detected readily, either visually or spectrophotometrically.

Experimental data and calculated values of the association constant for the primary reaction of bromophthalein magenta $\mathrm{E}$ with diphenylguanidine in benzene are given in table 1 . The initial concentration of bromophthalein magenta $\mathrm{E}, C_{a}$, was $2.5 \times$ $10^{-5} \mathrm{M}$. The molar concentration of diphenylguanidine at the moment of mixing is given in column 1 and the measured absorbancy after mixing, in column 2 . The equilibrium concentration of the primary salt, $\left[S_{1}\right]$, is $C_{a}\left(A_{s} / 0.5100\right) . \quad[A]=C_{a}-\left[S_{1}\right]$, and $[B]=$ $C_{b}-\left[S_{1}\right]$. Values for $K_{a s s n}$. (see eq 1 ) are given in column 6 ; the average value is $2.2 \times 10^{5}$. Values calculated similarly from data at $405 \mathrm{~m} \mu$, with the average value $2.3 \times 10^{5}$, are given in column 7 ; we consider these values to be less accurate, because the changes in absorbancy are smaller at this wavelength, and the calculations involve two limiting values that may be slightly in error (one for the indicator itself and one for the primary salt). As indicated in the table, the average value of $K_{a s s n}$. was computed from the data for increments of diphenylguanidine ranging from $1.0 \times 10^{-5} \mathrm{M}$ to $3.75 \times 10^{-5} \mathrm{M}$, inclusive. With very small increments of the base or increments close to the limiting concentration, the effect of any experimental error is magnified; also, there is evidence that diphenylguanidine is adsorbed to a small extent on glass, and errors from this source would be greater for low concentrations. According to studies by Hunter and Marriott [22], diphenylguanidine is somewhat associated in naph- thalene, through hydrogen bonding; any such association in benzene has no evident effect upon its reaction with bromophthalein magenta $\mathrm{E}$ at the concentrations under consideration.

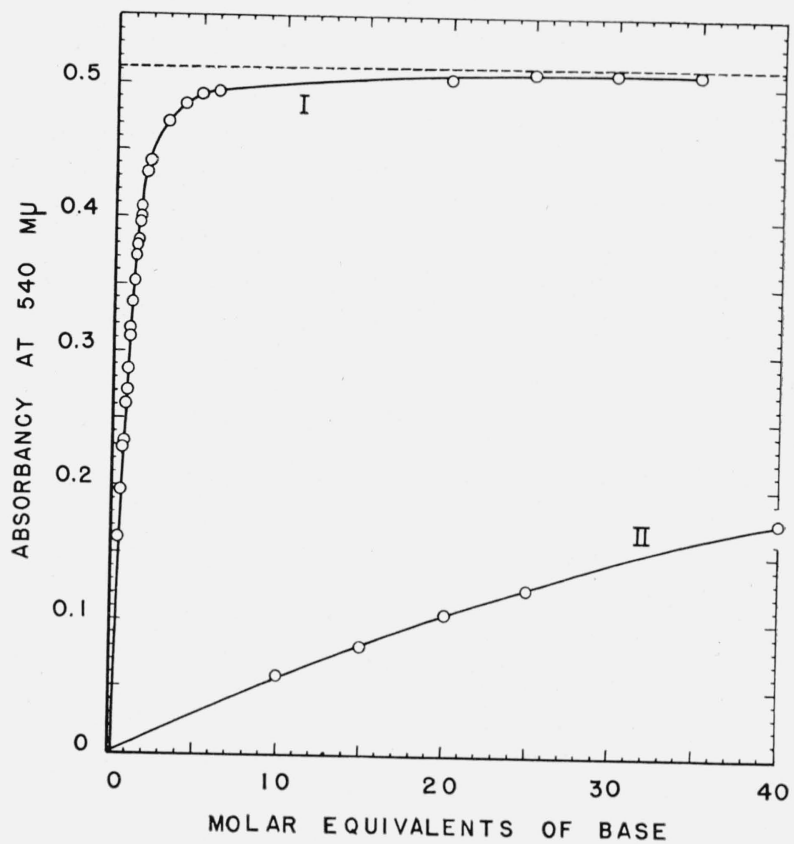

FIgURE 2. Change in absorbancy accompanying the primary reaction in benzene of $2.5 \times 10^{-5}-M$ bromophthalein magenta $E$ with $I$, diphenylguanidine and $I I$, triphenylguanidine; $5-\mathrm{mm}$ cells.

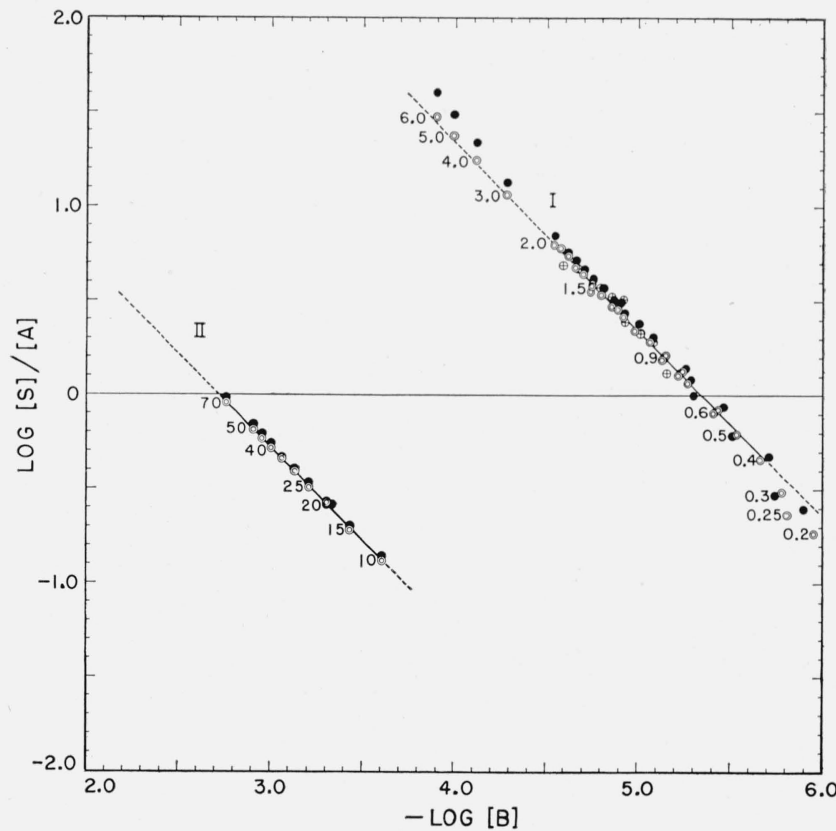

FIGURE 3. Graphical evaluation of the association constant for the primary reaction of bromophthalein magenta $E$, $2.5 \times 10^{-5}-M$ in benzene, with $I$, diphenylguanidine and $I I$, triphenylguanidine.

5 -mm cells. Numbers adjacent to experimental points indicate the number of moles of base per mole of the indicator. Double circles, values tor $540 \mathrm{~m} \mu$; solid circles, values for $405 \mathrm{~m} \mu$. Values indicated by a cross inscribed in a circle are for the primary salt of diphenylguanidine and bromophthalein magenta $\mathrm{E}$. 
TABLE 1. Experimental data and association constant for the primary reaction of bromophthalein magenta E with diphenylguanidine in benzene

\begin{tabular}{|c|c|c|c|c|c|c|}
\hline \multirow{3}{*}{$C_{b} a^{a}$} & \multicolumn{6}{|c|}{ From measurements at- } \\
\hline & \multicolumn{5}{|c|}{$540 \mathrm{~m} \mu$} & \multirow{2}{*}{$\underset{K_{\mathrm{assn}}}{\mathrm{m}_{\mu}}$} \\
\hline & $A_{\mathrm{s}} \mathrm{b}$ & {$\left[S_{1}\right]^{\mathrm{a}}$} & {$[A] \mathrm{ac}^{-}$} & {$[B]^{\mathrm{a}}$} & $K_{\mathrm{assn}}$ & \\
\hline $\begin{array}{l}0.5 \times 10^{5} \\
.75 \\
1.0 \\
1.25 \\
1.5 \\
1.5 \\
1.75 \\
1.875 \\
2.0 \\
2.0 \\
2.25 \\
2.25 \\
2.5 \\
2.75 \\
3.0 \\
3.125 \\
3.25 \\
3.5 \\
3.75 \\
3.75 \\
3.75 \\
3.75 \\
4.0 \\
5.0 \\
10 \\
15 \\
\text { Limiting value }\end{array}$ & $\begin{array}{l}0.0795 \\
.1198 \\
.1605 \\
.1962 \\
.2328 \\
.2281 \\
.2604 \\
.2739 \\
.2864 \\
.2933 \\
.3169 \\
.3102 \\
.3363 \\
.3517 \\
.3704 \\
.3790 \\
.3825 \\
.3958 \\
.4047 \\
.3994 \\
.4075 \\
.4067 \\
.4173 \\
.4413 \\
.4840 \\
.4949 \\
.5100\end{array}$ & $\begin{array}{l}0.3897 \times 10^{-5} \\
.5873 \\
.7868 \\
.9618 \\
1.141 \\
1.118 \\
1.276 \\
1.343 \\
1.404 \\
1.438 \\
1.553 \\
1.521 \\
1.649 \\
1.724 \\
1.816 \\
1.858 \\
1.875 \\
1.940 \\
1.984 \\
1.958 \\
1.998 \\
1.994 \\
2.046 \\
2.163 \\
2.373 \\
2.426 \\
2.500\end{array}$ & $\begin{array}{l}2.110 \times 10^{-5} \\
1.913 \\
1.713 \\
1.538 \\
1.359 \\
1.382 \\
1.224 \\
1.157 \\
1.096 \\
1.062 \\
0.9466 \\
.9794 \\
.8515 \\
.7760 \\
.6843 \\
.6422 \\
.6250 \\
.5598 \\
.5162 \\
.5422 \\
.5025 \\
.5064 \\
.4544 \\
.3368 \\
.1275 \\
.0740 \\
-. .-\end{array}$ & $\begin{array}{l}0.1103 \times 10^{-5} \\
.1627 \\
.2132 \\
.2882 \\
.3588 \\
.3819 \\
.4735 \\
.5324 \\
.5961 \\
.5623 \\
.6966 \\
.7294 \\
.8515 \\
1.026 \\
1.184 \\
1.267 \\
1.375 \\
1.560 \\
1.766 \\
1.792 \\
1.752 \\
1.756 \\
1.954 \\
2.837 \\
7.627 \\
12.57\end{array}$ & $\begin{array}{l}{ }^{*} 1.67 \times 10^{5} \\
{ }^{*} 1.89 \\
2.15 \\
2.17 \\
2.34 \\
2.12 \\
2.20 \\
2.18 \\
2.15 \\
2.41 \\
2.36 \\
2.13 \\
2.27 \\
2.17 \\
2.24 \\
2.28 \\
2.18 \\
2.22 \\
2.18 \\
2.01 \\
2.27 \\
2.24 \\
{ }^{2} .30 \\
{ }^{2} .26 \\
{ }^{2} .44 \\
{ }^{*} 2.61\end{array}$ & $\begin{array}{l}* 1.98 \times 10^{5} \\
\text { *1. } 62 \\
2.42 \\
1.99 \\
2.52 \\
2.10 \\
2.03 \\
2.33 \\
2.25 \\
2.50 \\
2.19 \\
2.16 \\
2.46 \\
2.41 \\
2.32 \\
2.49 \\
2.37 \\
2.40 \\
2.34 \\
2.34 \\
2.38 \\
2.38 \\
\text { *2. } 37 \\
\text { *2. } \\
\text { *2. } \\
\text { *2. } 2.90\end{array}$ \\
\hline \multicolumn{5}{|l|}{ Average ${ }^{d}$} & 2. $21 \times 10^{5}$ & 2. $32 \times 10^{5}$ \\
\hline
\end{tabular}

a In moles per liter of solution.

b Calculated from the average of 10 readings of the transmittancy.

- $C_{\mathrm{B}}=2.5 \times 10^{-5} \mathrm{~mole} / \mathrm{liter}$.

$\mathrm{d}$ Values marked with an asterisk were not included in the computation of the average.

A graphical means of evaluating the association constant is shown in figure 3 (line I), in which log $\left[S_{1}\right] /[A]$ is plotted against - $\log [B][1,20]$. As required by the reaction postulated, the experimental values fall on or very close to a line of slope -1 . As the line has been drawn, the intercept corresponds to the association constant $2.2 \times 10^{5}$.

From a solution that contained approximately $3.2 \times 10^{-3}-M$ bromophthalein magenta $\mathrm{E}$ and $0.015-M$ diphenylguanidine in benzene, rosettes of short, lustrous green needles deposited after several weeks. The supernatant liquid was decanted off, and the crystals were washed four times with benzene by decantation, then dried in a vacuum oven at room temperature. This solid was used in the preparation of three different stock solutions in benzene, on the assumption that it was the primary salt of bromophthalein magenta $\mathrm{E}$ and diphenylguanidine (molecular weight, 873.26). Absorbancy curves were obtained for these three solutions and for 10 others made from them by dilution. Within experimental error, the curve for a $2.5 \times 10^{-5}-M$ solution of the salt was the same as that for a solution made by mixing one molar equivalent of diphenylguanidine with $2.5 \times 10^{-5}-M \mathrm{BPM}-\mathrm{E}$. Because of the variation in the concentration of the solutions and the different cell lengths employed, the absorbancies were converted to the molar basis in computing the constant for the dissociation of $S_{1}$ into $A$ and $B$. The data obtained for one of the three series of solutions are presented in table 2 . Values for $K_{\text {dissn }}$. are given in column 5 and values for its reciprocal, $K_{a s s n}$., in column 6 . The average value thus found for $K_{a s s n}$. is $2.34 \times 10^{5}$. (The average based on all 13 solutions was $2.35 \times 10^{5}$.) This is nearly the same as the value obtained by mixing the indicator with different increments of diphenylguanidine; we regard it as less accurate because the measurements were made at a period when the temperature of the room was subject to more than the usual variation. Molar absorbancy curves for most of this series of solutions are shown in figure 4. They show fairly sharp isosbestic points near $355 \mathrm{~m} \mu$ and $455 \mathrm{~m} \mu$ (compare fig. 1). ${ }^{6}$ A third less well-marked intersection occurs near $295 \mathrm{~m} \mu$. In figure 3 , nine values for the salt are indicated by crosses inscribed in circles; four additional values are not shown because they coincided with ones obtained for mixtures of the indicator with the base. The values show a little scattering, but are close to line I.

In the study of the reaction of triphenylguanidine with bromoph thalein magenta $\mathrm{E}$, it was immediately apparent that triphenylguanidine is much less reactive than diphenylguanidine. (See fig. 2, curve II.) It was also evident that a secondary reaction overlaps the primary reaction. Consequently, in evaluating the primary association constant it was assumed that

${ }^{6}$ It will be observed that the vertical scale of fig. 4 is twice as long as that of fig. 1 . 


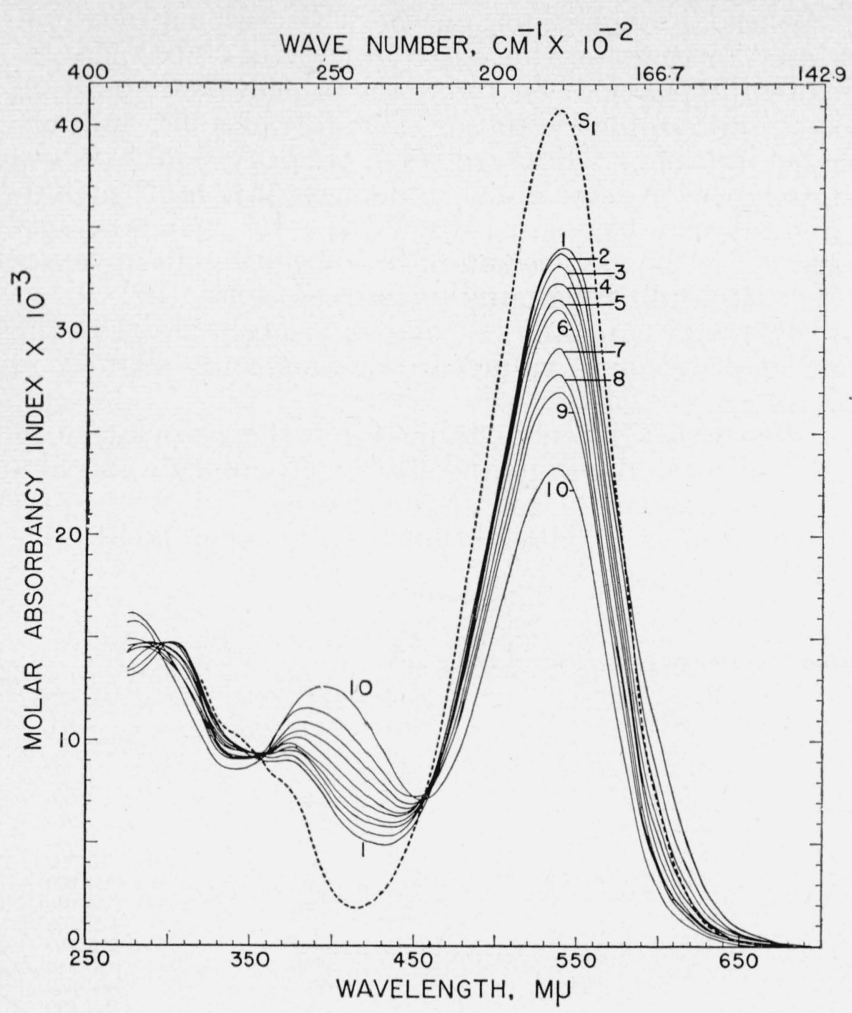

Figure 4. Effect of ditution on the molar absorbancy of the primary salt of bromophthalein magenta $E$ and diphenylguanidine in benzene.

Concentration of the salt in moles per liter $\times 10^{5}$ : (1) 15 , (2) 12 , (3) 9, (4) 7.5 , (5) 6 , (6) $5,(7) 4,(8) 3,(9) 2.4,(10) 1.6$. (S 1 ) $2.5 \times 10^{-5}-M$ BPM-E with 45 molar equivalents of diphenylguanidine.

TABLE 2. Dissociation constant of the primary salt of bromophthalein magenta $E$ and diphenylguanidine in benzene, and the corresponding association contant

\begin{tabular}{|c|c|c|c|c|c|}
\hline $\mathrm{C}_{8}{ }^{\mathrm{a}}$ & $\begin{array}{c}{ }^{a_{M}} \\
\text { at } 540 \mathrm{~m} \mu\end{array}$ & {$\left[\mathrm{S}^{1}\right]^{\mathrm{b}}$} & {$[A]^{\mathrm{be}}$} & $K_{\text {disen }}$ & $K_{\text {assn. }}{ }^{d}$ \\
\hline 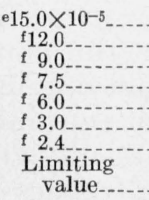 & $\begin{array}{l}34.00 \times 10^{3} \\
33.77 \\
33.10 \\
32.29 \\
31.49 \\
27.96 \\
26.97 \\
40.80\end{array}$ & $\begin{array}{c}12.50 \times 10^{-5} \\
9.932 \\
7.301 \\
5.936 \\
4.631 \\
2.056 \\
1.586\end{array}$ & $\begin{array}{l}2.500 \times 10^{-5} \\
2.068 \\
1.699 \\
1.564 \\
1.369 \\
0.9441 \\
.8135\end{array}$ & $\begin{array}{l}5.00 \times 10^{-6} \\
4.30 \\
3.95 \\
4.12 \\
4.05 \\
4.34 \\
4.17\end{array}$ & $\begin{array}{l}2.00 \times 10^{5} \\
2.32 \\
2.53 \\
2.43 \\
2.47 \\
2.31 \\
2.40\end{array}$ \\
\hline Averag & & & & $4.28 \times 10^{-6}$ & $2.34 \times 10^{5}$ \\
\hline
\end{tabular}

a Initial concentration of the primary salt in moles per liter of solution.

$\mathrm{b}$ In moles per liter of solution.

- $[B]=[A]$.

d Reciprocal of $K_{\text {disso. }}$

e Stock solution.

i Preplared by dilution of stock solution.

the limiting curve for the reaction is the same as the one found for the reaction with diphenylguanidine (the one designated $S_{1}$ in all of the figures). This is a very reasonable assumption, as triethylamine, diphenylguanidine, and di-o-tolylguanidine have all been found to have the same limiting curve in reacting with bromophthalein magenta E. (See [1], fig. 8.) The experimental data and calculated values of the association constant for the reaction of bromo-

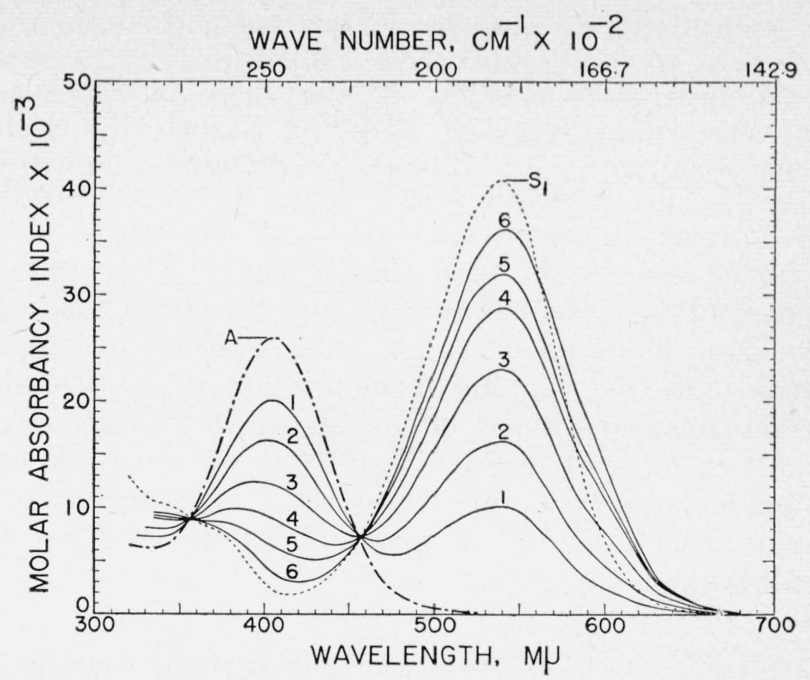

Figure 5. Effect of triphenylguanidine on the molar absorbancy of $2.5 \times 10^{-5}-M$ bromophthalein magenta $E$ in benzene.

5-mm cells. A, BPM-E without added base; 1 to 6 , with $25,50,100,200,400$, and 1,600 molar equivalents of triphenylguanidine, respectively; $S_{1}, 2.5 \times 10^{-5}-M$ BPM-E with 45 molar equivalents of diphenylguanidine.

phthalein magenta $\mathrm{E}$ with triphenylguanidine in benzene are given in table 3 . The average value for

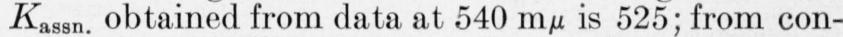
siderations similar to those discussed for diphenylguanidine, this is probably more nearly correct than the value 547 , which was obtained from data at 405 $\mathrm{m} \mu$.

Graphical evaluation of the association constant for the primary reaction is shown in figure 3 , line II. The postulate that the primary reaction corresponds to the simple pattern, $A+B \rightleftharpoons S_{1}$, and the assumption of the same limiting curve as for the reaction of BPM-E with diphenylguanidine appear wellgrounded, as the values fall on or very close to a line of slope -1 ; the intercept of this line with the $x$-axis for $\log \left[S_{1}\right] /[A]=0$ corresponds to the association constant 525 .

TABLE 3. Experimental data and association constant for the primary reaction of bromophthalein magenta $E$ with triphenylguanidine in benzene

\begin{tabular}{|c|c|c|c|c|c|c|}
\hline \multirow{3}{*}{$C_{b^{\mathrm{a}}}$} & \multicolumn{6}{|c|}{ From measurements at- } \\
\hline & \multicolumn{5}{|c|}{$540 \mathrm{~m} \mu$} & \multirow{2}{*}{$\begin{array}{c}405 \mathrm{~m} \mu \\
K_{\mathrm{BSBD}}\end{array}$} \\
\hline & $A_{\mathrm{s}} \mathrm{b}$ & {$\left[S_{1}\right]_{\mathrm{a}}$} & {$[A]^{\mathrm{a}}$} & {$[B]^{\mathrm{a}}$} & $K_{\text {ansn. }}$. & \\
\hline $\begin{array}{l}25 \times 10^{-5} \\
37.5 \\
50 \\
50 \\
50 . \\
62 . \\
75 \\
87.5 \\
100 \\
112 . \\
125 \\
175 \\
175\end{array}$ & $\begin{array}{l}0.0592 \\
.0819 \\
.1055 \\
.1080 \\
.1246 \\
.1445 \\
.1612 \\
.146 \\
.1894 \\
.2026 \\
.2447\end{array}$ & $\begin{array}{l}0.2902 \times 10^{-5} \\
.4015 \\
.5172 \\
.5292 \\
.6108 \\
.7080 \\
.7899 \\
.8559 \\
.9280 \\
.9927 \\
1.199\end{array}$ & $\begin{array}{l}\text { o } 2.210 \times 10^{-5} \\
\text { e } 2.099 \\
\text { d } 1.983 \\
\text { d } 1.991 \\
\text { o } 1.889 \\
\text { d } 1.812 \\
\text { d } 1.730 \\
\text { o } 1.644 \\
\text { d } 1.592 \\
\text { d } 1.527 \\
\text { d } 1.321\end{array}$ & \begin{tabular}{|c|}
$24.71 \times 10^{-5}$ \\
37.10 \\
49.48 \\
49.47 \\
61.89 \\
74.29 \\
86.71 \\
99.14 \\
111.6 \\
124.0 \\
173.8
\end{tabular} & $\begin{array}{l}531 \\
516 \\
527 \\
537 \\
522 \\
526 \\
527 \\
525 \\
522 \\
524 \\
522\end{array}$ & $\begin{array}{l}560 \\
539 \\
542 \\
525 \\
551 \\
541 \\
535 \\
553 \\
555 \\
559 \\
557\end{array}$ \\
\hline \multicolumn{5}{|c|}{ A verage } & 525 & 547 \\
\hline
\end{tabular}

a In moles ner liter of solution.

b Calculated from the average of 10 readings of the transmittancy.

- $C_{a}=2.5 \times 10^{-5}$ mole/liter; limiting value, 0.5100 .

d $C_{a}=2.52 \times 10^{-5}$ mole/liter; limiting value, 0.5143 . 
Representative absorbancy curves for the primary reaction of bromophthalein magenta $\mathrm{E}$ with triphenylguanidine (see fig. 5) closely resemble those for the primary reaction of BPM-E with diohenylguanidine (see fig. 1). The curves in figure 5 show the same isosbestic points near 355 and $455 \mathrm{~m} \mu$. It will be noticed, however, that curves 2 through 6 show greater absorbancy than that of curve $S_{1}$ at wavelengths longer than about $560 \mathrm{~m} \mu$; the corresponding solutions had a purple tinge. These effects are indicative of the overlapping of the primary with a secondary reaction. Similar effects shown in figure 4 (notably in curves 1 through 3 ) are very likely caused by a partial secondary reaction in the most concentrated solutions of the salt of bromophthalein magenta $\mathrm{E}$ and diphenylguanidine.
With the inclusion of the two association constants reported in this paper, a total of 11 association constants have been obtained at this Bureau from spectrophotometric data. These values are summarized in table 4 . Some of these are provisional values, having been determined under less favorable experimental conditions. However, the redetermined value for the association of bromophthalein magenta $\mathrm{E}$ with diphenylguanidine agrees with the earlier provisional constant [1], and it is probable that the other provisional values are at most only slightly in error.

The value given in table 4 for the association of $\mathrm{N}, \mathrm{N}$-dimethylaniline and hydrogen chloride in chloroform was calculated at this Bureau [23] from spectrophotometric data obtained in another laboratory [24].

TABLE 4. Association constants for primary acid-base reactions in inert solvents

\begin{tabular}{|c|c|c|c|}
\hline Base & Acid & Solvent & $\mathrm{K}_{\text {asan. }}{ }^{\mathrm{a}}$ \\
\hline Tribenzylamine..... & Trinitro- $m$-cresol & Benzene... & b 450 \\
\hline Triphenylguanidine & Bromophthalein magenta $\mathrm{E}$ & . & 525 \\
\hline Tribenzylamine & Picric acid & ..... do & b 1,600 \\
\hline Di- $n$-butylamine & Bromophthalein magenta $\mathrm{E}$ & do & e 15,500 \\
\hline Triethylamine..... & - do & ..... do & e 23,000 \\
\hline Do & Bromophthalein magenta $\mathrm{B}$. & ..... do & c 23,000 \\
\hline Piperidine & Bromophthalein magenta $\mathbf{E}$ & . do & c 120,000 \\
\hline Diphenylguanidine........... & do & do & 220,000 \\
\hline Do & Bromophthalein magenta $\mathrm{B}$ & . do & c 220,000 \\
\hline Di-o-tolylguanidine & Bromophthalein magenta $\mathrm{E}$ & do & c 860,000 \\
\hline Do & Bromophthalein magenta $B$ & do & - 860,000 \\
\hline $\mathrm{N}, \mathrm{N}$-Dimethylaniline & Hydrogen chloride. & Chloroform & d $67,000,000$ \\
\hline
\end{tabular}

a Concentrations expressed in moles per liter; $t=25^{\circ} \mathrm{C}$.

b See [20].

- Provisional value; see [1].

d Reciprocal of dissociation constant given in [23].

It is of particular interest that the association constant for the reaction of tribenzylamine with picric acid in benzene is the same as the value obtained from measurements by Maryott of the dielectric constant of benzene solutions of tribenzylammonium picrate [25]. The suggestion has been made $[26,27]$ that tribenzylammonium picrate may exist in isomeric forms, $\mathrm{R}_{3} \mathrm{~N}$.HPi and $\mathrm{R}_{3} \mathrm{NH}^{+} \mathrm{Pi}^{-}$, which are slowly interconvertible, but the arguments used in support of this hypothesis are not entirely convincing. No anomalies that might be explained on this basis were observed in spectrophotometric studies of the reaction of tribenzylamine with picric acid in benzene [20], and Maryott, in measuring the dipole moment of tribenzylammonium picrate, could not detect such an equilibrium [25]. Witschonke and Kraus [28] were also unable to furnish experimental support for such an isomerism.

One of the authors has already pointed out [23] that in an inert solvent there is no essential difference in the product of the reaction of a base with a "Brønsted" acid and the product of the reaction of a base with a "Lewis" acid. Both are in effect highly polar addition compounds. ${ }^{7}$ To illustrate

7 In this paper they are referred to as addition compounds or as "salts", although there may be some disagreement with this terminology. Kraus and Fuoss have applied the term "ion-pair" to addition compounds of the type listed as "Bronsted salts" in table 5 [29]. For other points of view in regard to the term "salt", see [30], p. 159 and [31], p. 88 . this point, a number of examples of dipole moments of such compounds, taken from the work of other investigators, have been assembled in table 5. The dipole moment in Debye units $\left(\mu \times 10^{18} \mathrm{esu}\right)$ is given in the third column. The first five examples are Lewis salts, and the next group are Brønsted salts. The reader will note that the dipole moments of the tributylammonium halides are of about the same magnitude as the moments of the trialkylaminesulfur trioxide addition compounds and of pyridinesulfur dioxide. The dipole moments of trialkylammonium picrates are about one and a half times as great. In contrast, the dipole moments of the constituent acids and bases are considerably smaller, showing that in the formation of the salts there is appreciable separation of charge.

The similarity in the reactions that lead to the formation of the two types of salts is illustrated by the following examples:

$$
\begin{gathered}
\mathrm{Et}_{3} \mathrm{~N}:+\mathrm{SO}_{2} \rightleftharpoons \mathrm{Et}_{3} \mathrm{~N}^{+}: \mathrm{SO}_{2}{ }^{-} \\
\mathrm{Et}_{3} \mathrm{~N}:+\mathrm{HCl} \rightleftharpoons \mathrm{Et}_{3} \mathrm{~N}: \mathrm{H}^{+} \ldots \mathrm{Cl}^{-}
\end{gathered}
$$

In the first reaction, the separation of charge is brought about by displacement of the "lone pair" of electrons on the nitrogen toward the sulfur atom. In the second reaction, the proton of hydrogen 
TABLE 5. Dipole moments of salts and their constituent acids and bases

\begin{tabular}{|c|c|c|}
\hline Compound & Solvent & $\mu \times 10^{18} \mathrm{esu}$ \\
\hline \multicolumn{3}{|c|}{ Lewis salts } \\
\hline Trimethylamine-sulfur dioxide.. & Benzene...... & \multirow{5}{*}{$\begin{array}{l}\text { a } 4.9 \\
\text { a } 6.84 \\
\text { a } 7.3 \\
\text { a } 7.2 \\
\text { a } 6.2\end{array}$} \\
\hline Triethylamine-sulfur trioxide.... & -... do do & \\
\hline Do & Dioxane & \\
\hline Tri- $n$-butylamine-sulfur trioxide..... & Benzene................ & \\
\hline Pyridine-sulfur dioxide & -..... do & \\
\hline \multicolumn{3}{|c|}{ Brønsted salts } \\
\hline Tributylammonium chloride__- & Benzene & \multirow{16}{*}{$\begin{array}{l}\text { b } 7.17 \\
\text { e } 7.3 \\
\text { b } 7.61 \\
\text { b } 8.09 \\
\text { d } 11.7 \\
\text { e } 12.7 \\
\text { d } 11.9 \\
\text { e } 10.7 \\
\text { d } 12.2 \\
\text { c } 11.7 \\
\text { d } 11.9 \\
\text { e } 10.7 \\
\text { e } 11.1 \\
\text { e } 13.6 \\
\text { d } 11.8 \\
\text { f } 12.0\end{array}$} \\
\hline Do & Toluene............... & \\
\hline Tributylammonium bromide... & Benzene......... & \\
\hline Tributylammonium iodide....- & So do & \\
\hline Triethylammonium picrate & $\ldots$ do ........ & \\
\hline Tripropylammonium picrate & Dioxane & \\
\hline Tri- $n$-butylammonium picrate & Benzene & \\
\hline Do & Carbon disulfide...... & \\
\hline Do & Dioxane & \\
\hline Do & Toluene............ & \\
\hline Triisoamylammonium picrate.- & Benzene & \\
\hline Do & Carbon disulfide...... & \\
\hline Do & Carbon tetrachloride.- & \\
\hline Do & Dioxane & \\
\hline Diethylbenzylammonium picrate _... & Benzene................... & \\
\hline Tribenzylammonium picrate........ & ...... do & \\
\hline \multicolumn{3}{|c|}{ Amines } \\
\hline Trimethylamine $\ldots . .$. & None (gaseous state) .. & g 0.65 \\
\hline Triethylamine & Benzene................... & g 0.8 \\
\hline Tri- $n$-butylamine... & - $d 0_{\ldots} \ldots$ & a 0.77 \\
\hline Pyridine & - & g 2.3 \\
\hline Dimethylaniline _.................... & $\ldots$ do $0_{\ldots} \ldots \ldots$ & g 1.6 \\
\hline \multicolumn{3}{|c|}{ Acids } \\
\hline Sulfur dioxide & None (gaseous state) _. & g 1.61 \\
\hline Sulfur trioxide & ..... do & g 0 \\
\hline Hydrogen chloride.... & . do & g 1.03 \\
\hline Hydrogen bromide.... & & g 0.79 \\
\hline Hydrogen iodide & - do & g 0.38 \\
\hline Picric acid & Benzene.............. & f 1.75 \\
\hline
\end{tabular}

a Reference [24]; $t=25^{\circ} \mathrm{C}$.

b J. A. Geddes and C. A. Kraus, Trans. Faraday Soc. 32, $585(1936) ; t=25^{\circ} \mathrm{C}$ - V. Deitz and R. M. Fuoss, J. Am. Chem. Soc. 60, $2394(1938) ; t=35^{\circ}$ C.

d. A. Maryott, J. Research NBS 41, 1 (1948) RP 1896; $t=30^{\circ} \mathrm{C}$.

f $[25] ; t=30^{\circ} \mathrm{C}$.

g L. G. Wesson, Tables of electric dipole moments (Laboratory for Insulation g L. G. Wesson, Tables of electric dipole moments (Laboratory ior Insulation
Research, Massachusetts Institute of Technology, Cambridge, Mass., April 1947).

chloride is attracted toward the lone pair of electrons on the nitrogen; it should not be regarded as transferred completely to the nitrogen, however, but as forming a bridge between nitrogen and chlorine. This means that in each of the examples given, the reaction is to be thought of as yielding only one product. Representation of triethylammonium chloride, as well as other Brønsted salts, as polar, hydrogen-bonded addition compounds is consistent with the conclusion of Walden [30] and of Kraus [32] from conductance measurements, that in inert solvents such salts are extremely weak electrolytes.

According to the Brønsted-Lowry definition scheme, the reaction between triethylamine and hydrogen chloride would be formulated as follows:

$$
\underset{\left(\text { acid }_{1}\right)}{\mathrm{HCl}} \rightleftharpoons \mathrm{H}^{+}+\underset{\left(\text { base }_{1}\right)}{\mathrm{Cl}^{-}}
$$

$$
\frac{\underset{\left(\text { base }_{2}\right)}{\mathrm{Et}_{3} \mathrm{~N}:}+\mathrm{H}^{+} \rightleftharpoons \underset{\left(\text { acid }_{2}\right)}{\rightleftharpoons} \underset{\left(\text { base }_{2}\right)}{\mathrm{Et}_{3} \mathrm{~N}:}+\underset{\left(\text { acid }_{1}\right)}{\mathrm{HCl}} \rightleftharpoons \underset{\left(\text { acid }_{2}\right)}{\mathrm{E} \mathrm{NH}_{3} \mathrm{NH}^{+}}+\underset{\left(\text { base }_{1}\right)}{\mathrm{Cl}^{-}}}{\mathrm{Cl}^{-}} .
$$

That is, the reaction would be depicted as the simultaneous release of a proton by hydrogen chloride (eq 1) and addition of a proton by triethylamine (eq 2), the net reaction (eq 3) being the complete transfer of a proton from hydrogen chloride to triethylamine. In such a reaction, the product would consist of two discrete particles. In considering the question of acidity and basicity in benzene in an exploratory way [12], Brønsted clearly conceived of acid-base reactions as conforming to eq 3. However, he recognized that the ions of a salt in benzene and other inert solvents are almost completely associated electrically and spoke of a transition from the electrovalent to the covalent state. His concluding statement was "The provisory nature of these measurements must be expressly pointed out. An exhaustive study of the molecular state in benzene and similar solvents must precede the exact quantitative investigation of acidic and basic strengths in these solvents."

There is much corroborative evidence in the literature that hydrogen acids form addition compounds with bases in the absence of water and other bases, and recognition of this fact is implicit, if not actually expressed, in many articles. For instance, in cryoscopic studies of the dissociation of pyridine o-chlorophenoxide or quinoline o-chlorophenoxide in benzene and in p-dichlorobenzene, Glass and Madgin formulated the equilibrium in terms of the association $\mathrm{BN}+\mathrm{HOR} \rightleftarrows \mathrm{BNHOR}$ [33]. The acid-base dissociation of phenylammonium, phenyldimethylammonium, and pyridonium picrates in nitrobenzene was studied by Witschonke and Kraus by the conductance method [28], and they recognized that the dissociation constant "provides a quantitative measure of the relative strength of acids or bases in non-aqueous neutral solvents." However, it appears to us more logical to express such acidbase equilibria in terms of an association constant, and we believe that if the acid-base equilibria studied by various other investigators had been formulated in this way instead of as a dissociation, the analogy in the behavior of Lewis acids and Brønsted acids with bases would not have gone unrecognized for so long. To think of acid-base equilibria in terms of dissociation was natural, of course, because of the customary way of expressing the relative strengths of acids and bases in terms of ionic dissociation constants in water, especially when the starting material was so frequently a salt (which is usually the most convenient substance to study).

Although, as just indicated, a number of investigators have arrived independently at the conclusion that acid-base reactions in inert media are addition reactions (and thus conform to the Lewis concept), the problem remains of harmonizing this view with 
the behavior of acids and bases in solvents such as water. In their well-known book [31], Luder and Zuffanti discussed the reaction between hydrogen chloride and water and, as a means of unifying the Lewis and Brønsted-Lowry concepts of acidity, suggested that formation of the coordinate bond and ionization may occur simultaneously, as indicated by the following equation:

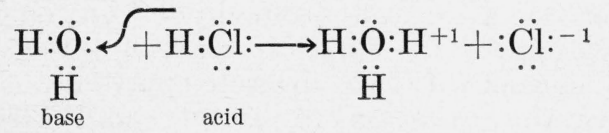

However, it seems to us that a clear understanding of the mechanism of such reactions is not possible without consideration of the effect of any excess of base. In aqueous solutions, the solvent itself plays the role of a base, as has long been recognized, but in order to render the formulation of a reaction as simple as possible, the role of the solvent is usually ignored. This concession to convenience has had additional justification in the lack of concrete knowledge of the extent to which the solvent becomes bound to dissolved particles, but it has led to incorrect interpretations. A partial step toward acknowledging the role of water has been made in the now quite general practice of indicating the formula of the hydrogen ion in aqueous solutions as $\mathrm{H}_{3} \mathrm{O}^{+}$or $\mathrm{H}_{2} \mathrm{OH}^{+}$. Some time ago, however, Huggins [34, 35] concluded that hydrogen ions are best considered as $\mathrm{H}_{2} \mathrm{OHOH}_{2}+$ ions. If this view is accepted, the stepwise reaction of hydrogen chloride with water can be formulated as follows:

$$
\begin{gathered}
\mathrm{H}_{2} \mathrm{O}+\underset{\text { acid }}{\mathrm{HCl}} \rightleftarrows \mathrm{H}_{2} \mathrm{OH}^{+} \ldots \mathrm{Cl}^{-}, \\
\mathrm{H}_{2} \mathrm{OH}^{+} \ldots \mathrm{Cl}^{-}+\mathrm{H}_{2} \mathrm{O} \rightleftarrows \mathrm{H}_{2} \mathrm{OH}^{+} \ldots \mathrm{OH}_{2}+\mathrm{Cl}^{-} .
\end{gathered}
$$

We believe there is strong experimental support for this formulation of the reaction. The product of the first step is an addition compound with a hydrogen bridge between oxygen and chlorine. The second step is the displacement of the chloride ion by water, not necessarily because water is the stronger base, but because it is present in such large excess. The proton now forms a bridge between oxygen and oxygen. (The chloride ion may also be solvated, but such solvation is probably of secondary importance.) The first step would naturally be obscured when hydrogen chloride is added to a large volume of water, and the apparent reaction would be

$$
2 \mathrm{H}_{2} \mathrm{O}+\mathrm{HCl} \rightleftarrows \mathrm{H}_{2} \mathrm{OH}^{+} \mathrm{HH}_{2}+\mathrm{Cl}^{-} \text {. }
$$

In a similar way, the reaction of an ammonia derivative, say trimethylamine, with water can be formulated as a two-step reaction:

$$
\begin{gathered}
\underset{\text { base }}{\left(\mathrm{CH}_{3}\right)_{3} \mathrm{~N}}+\underset{\text { acid }}{\mathrm{HOH}} \rightleftarrows\left(\mathrm{CH}_{3}\right)_{3} \mathrm{NH}^{+} \ldots \mathrm{OH}^{-} \\
\left(\mathrm{CH}_{3}\right)_{3} \mathrm{NH}^{+} \ldots \mathrm{OH}^{-}+\mathrm{H}_{2} \mathrm{O} \rightleftarrows\left(\mathrm{CH}_{3}\right)_{3} \mathrm{NH}^{+} \mathrm{OH}_{2}+\mathrm{OH}^{-} .
\end{gathered}
$$

In this case also, the first step is addition and the second step displacement. The over-all reaction then becomes

$$
\left(\mathrm{CH}_{3}\right)_{3} \mathrm{~N}+2 \mathrm{H}_{2} \mathrm{O} \rightleftarrows\left(\mathrm{CH}_{3}\right)_{3} \mathrm{NHOH}_{2}+\mathrm{OH}^{-} .
$$

The first step is essentially the same as in Moore and Winmill's formulation of the reaction of an amine with water $[36,37]$, but the second step differs in being a displacement rather than a dissociation. In our view, the formulation currently in vogue for such a reaction, namely,

$$
\left(\mathrm{CH}_{3}\right)_{3} \mathrm{~N}+\mathrm{H}_{3} \mathrm{O}^{+} \rightleftarrows\left(\mathrm{CH}_{3}\right)_{3} \mathrm{NH}^{+}+\mathrm{H}_{2} \mathrm{O},
$$

obscures the real nature of the reaction. ${ }^{8}$

We have presented quantitative evidence that an addition product is formed when a base and a Brønsted acid are brought together in an inert solvent like benzene. This evidence provides support for the first step in our proposed two-step mechanism for the reaction of an amine with water. What experimental evidence is there to justify the second step? A few examples will illustrate how a variety of approaches have led to the conclusion that whenever the proton is attached to an ammonium nitrogen, it has a marked tendency to form a bridge to a second electronegative atom.

Walden and Birr measured the mobility of three isomeric ions - tetramethylammonium, diethylammonium, and mono- $n$-butylammonium-in water and in methyl cyanide. In methyl cyanide, all three ions had nearly the same mobility. In water, the mobility of tetramethylammonium ion was the greatest, that of butylammonium ion was the smallest, and that of diethylammonium ion was intermediate. The authors concluded that the three ions are not solvated to any extent in methyl cyanide, and tetramethylammonium ion is not solvated in water, but incompletely alkylated ammonium ions are solvated in water. The number of water molecules surrounding butylammonium ion is greater than the number surrounding diethylammonium ion [38]. We may picture butylammonium ion as having the formula $\mathrm{BuN}\left(\mathrm{HOH}_{2}\right)_{3}{ }^{+}$and diethylammonium ion as having the formula $\mathrm{Et}_{2} \mathrm{~N}\left(\mathrm{HOH}_{2}\right)_{2}{ }^{+}$. Huggins expressed the view that "the larger the number of [hydrogen] bridges connecting a given nitrogen to neighboring oxygens, the weaker each bridge is, hence it may be that an ammonium ion in water solution is a terminal for only one, two or three bridges, on the average, at ordinary temperatures, instead of four . . ." [35]. However, TrotmanDickenson, on the basis of later evidence, concluded that solvation by water is greater for secondary ammonium ions than for tertiary ammonium ions, and still greater for primary ammonium ions [39].

Measurements of the ionic dissociation of various completely substituted and partially substituted

8 The reaction $\left(\mathrm{CH}_{3}\right)_{3} \mathrm{~N}+\mathrm{H}_{2} \mathrm{O} \stackrel{+}{\mathrm{H}} \mathrm{OH}_{2} \rightleftarrows\left(\mathrm{CH}_{3}\right)_{3} \mathrm{~N}_{\mathrm{H}}^{+} \mathrm{OH}_{2}+\mathrm{H}_{2} \mathrm{O}$ may also occur but probably plays a minor role because of the minute concentration of free ions present in water. This reaction, of course, is a displacement. 
ammonium salts in different organic solvents, performed by Kraus and Fuoss and their collaborators, led to the following conclusions with respect to the latter group of salts [40]: "In solvents that have no affinity for the proton, there is a specific interaction, due to the proton, between the positive and the negative ion. In a solvent such as pyridine, which has a marked affinity for the proton, interaction takes place between the proton and the solvent molecules, rather than between the proton and the negative ion. Further investigation is required to fully elucidate the interaction that occurs in systems of this kind."

Earlier in this paper, mention was made of the secondary reaction that overlaps the primary reaction of bromophthalein magenta $\mathrm{E}$ with triphenylguanidine and that occurs when bromophthalein magenta is mixed with a large excess of diphenylguanidine. As will be shown in the next section, spectrophotometric studies of this secondary reaction have furnished new and more concrete evidence of proton-bridge formation between ammonium nitrogen and other electronegative atoms.

\section{The Secondary Reaction}

The curves in figure 6 , obtained for mixtures of bromophthalein magenta $\mathrm{E}$ and diphenylguanidine

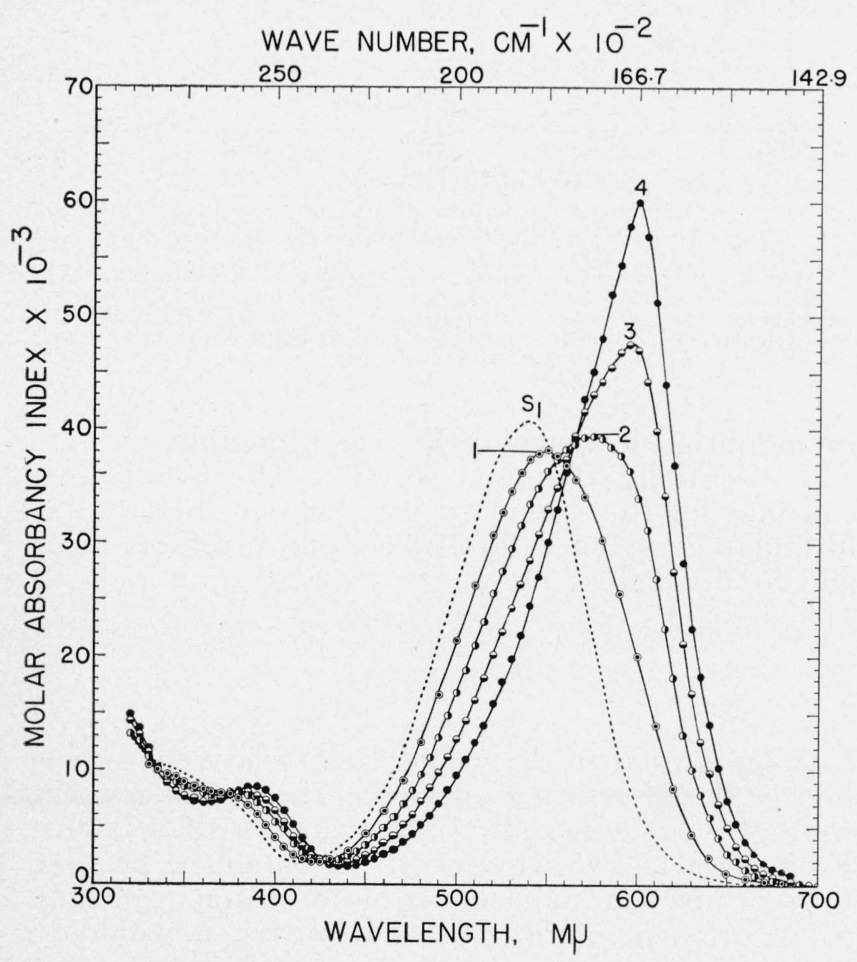

FIgure 6. Change in molar absorbancy of benzene solutions with variation in the concentration of bromophthalein magenta $E$ and diphenylguanidine

$S_{1}, 2.5 \times 10^{-5}-M$ BPM-E with 45 molar equivalents of diphenylguanidine; 1 , $2.5 \times 10^{-5}-M$ BPM-E with $0.04-M$ diphenylguanidine; $2,2.5 \times 10^{-4}-M$ BPM-E
with $0.0675-M$ diphenylguanidine; 3 - $10 \times 10^{-3}-M$ BPM $-\mathrm{E}$ with $0.045-M$ diphenylguanidine; $4,3.2 \times 10^{-3}-M$ BP M-E with $0.015-M$ diphenylguanidine. in benzene, show that at high concentrations of the indicator and base, the maximum absorbancy shifted from 540 to $600 \mathrm{~m} \mu$. The accompanying change in color was from magenta to a deep purple. The curves in figure 7 , obtained for mixtures of BPM-E and triphenylguanidine, exhibit a similar shift at high concentrations. If, instead of adding an excess of diphenylguanidine to the benzene solution containing $S_{1}$, the benzene was largely replaced by ethanol (figs. 8 and 9) or by pyridine (fig. 10), the maximum absorbancy shifted in a similar way, and the color changed to blue. In figure 9 , the curve obtained for a mixture of $2.5 \times 10^{-5}-M$ bromophthalein magenta $\mathrm{E}$ with 50 molar equivalents of diphenylguanidine in 96 percent ethanol-4 percent benzene by volume (curve 2) is practically identical with the molar absorbancy curve for the tetraethylammonium salt of BPM-E in ethanol (curve 3). It was not possible to prepare sufficiently concentrated solutions of bromophthalein magenta $\mathrm{E}$ with either di- or triphenylguanidine to shift the color completely to blue, but it is evident from comparison of these five figures that for all four bases (diphenylguanidine, triphenylguanidine, ethanol, and pyridine), the shift in the curves was of the same general character, and that the limiting curve would be very similar to that of the tetraethylammonium salt.

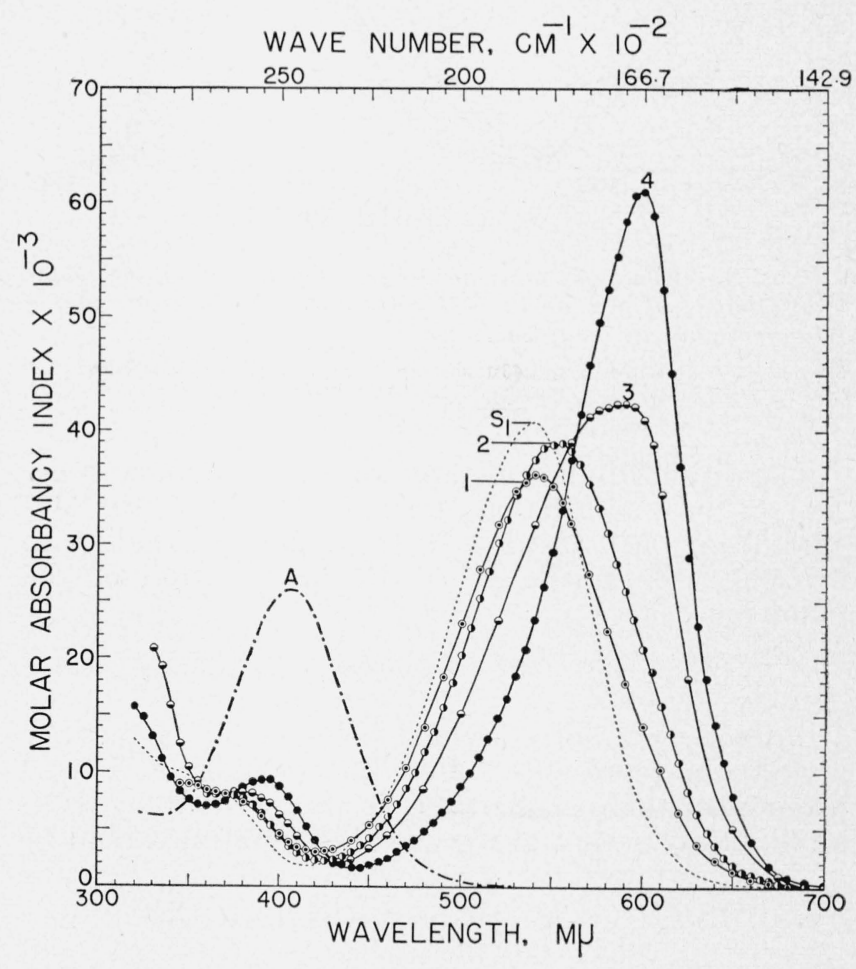

FIGURE 7. Change in molar absorbancy of benzene solutions with variation in the concentration of bromophthalein magenta $E$ and triphenylguanidine

A, $2.5 \times 10^{-5}-M$ BPM-E; $S_{1}, 2.5 \times 10^{-5}-M$ BPM-E with 45 molar equivalents of diphenylguanidine; $1,2.5 \times 10^{-5-} M$ BPM-E with $0.04-M$ triphenylguanidine; 2 $2.5 \times 10^{-5}-M$ BPM-E with $0.2-M$ triphenylguanidine; $3,5.0 \times 10^{-4}-M$ BPM-E with $0.2-M$ triphenylguanidine; $4,2.0 \times 10^{-3}-M$ BPM-E with $0.05-M$ triphenylguanidine. 


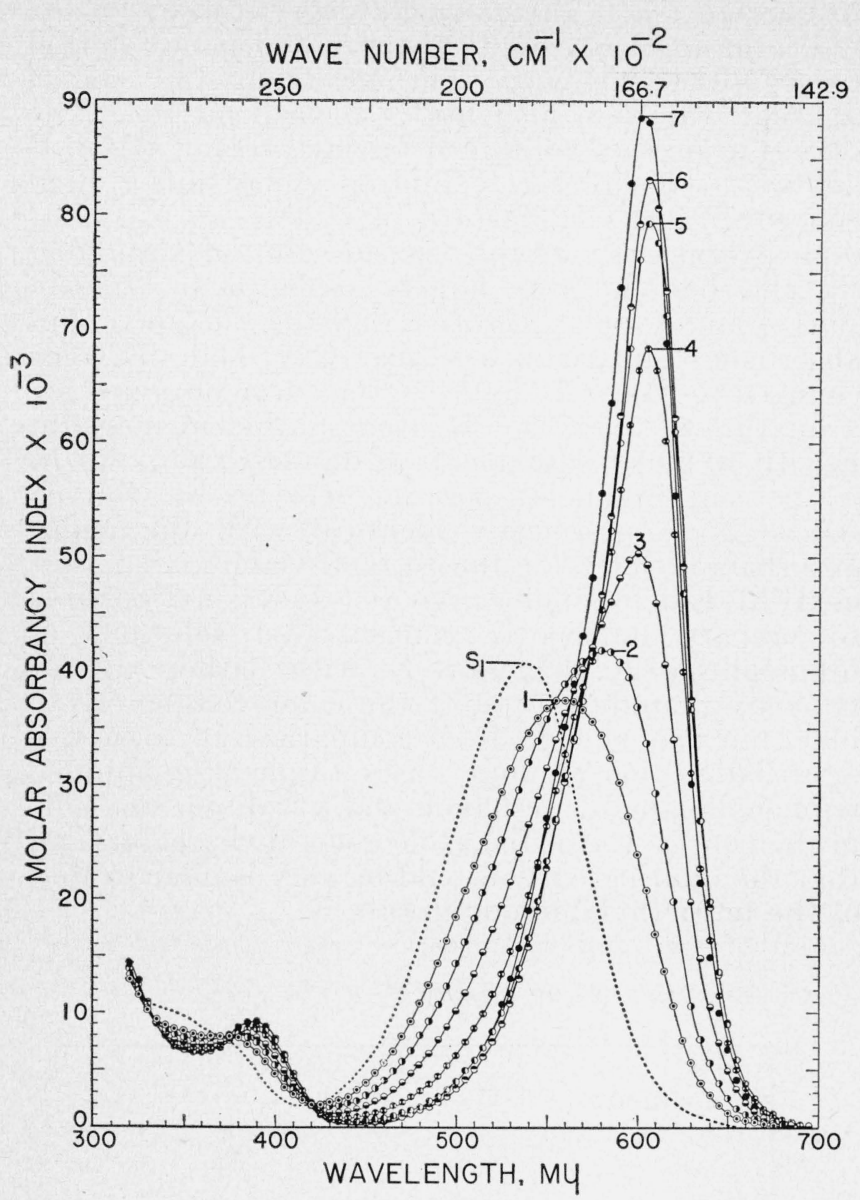

FIgure 8. Effect of replacing benzene by ethanol on the molar absorbancy of a $2.5 \times 10^{-5}-M$ solution of the primary salt of bromophthalein magenta $E$ and diphenylguanidine.

$S_{1}, 2.5 \times 10^{-5}-M$ BPM-E and 45 molar equivalents of diphenylguanidine; 1 to $7,2.5 \times 10^{-5}-M$ BPM-E, 50 molar equivalents of diphenylguanidine, and 10, 20 , $30,40,50,60$, and 97 percent of ethanol by volume, respectively.

The equilibrium constant for the secondary reaction of bromophthalein magenta $\mathrm{E}\left(2.5 \times 10^{-5}-M\right)$ with from $0.01-M$ to $0.04-M$ diphenylguanidine in benzene was calculated on the assumption of the following reaction.

$$
S_{1} \text { (primary salt) }+\mathrm{B} \text { (base) } \rightleftarrows S_{2} \text { (secondary salt). }
$$

If diphenylguanidine (which behaves like a tertiary amine) is represented by the formula $R_{3} \mathrm{~N}$ and bromophthalein magenta $\mathrm{E}$ is represented by $\mathrm{HX}$, an alternative way of writing this equation would be

$$
\mathrm{R}_{3} \mathrm{NH}^{+} \ldots \mathrm{X}^{-}+\mathrm{R}_{3} \mathrm{~N} \rightleftarrows\left(\mathrm{R}_{3} \mathrm{NH}^{+} \mathrm{NR}_{3}\right) \mathrm{X}^{-} .
$$

The equilibrium constant corresponding to the first equation is

$$
K_{2}=\frac{\left[S_{2}\right]}{\left[S_{1}\right][B]} .
$$

At the high concentrations of diphenylguanidine concerned; the concentration of $A$ (unreacted

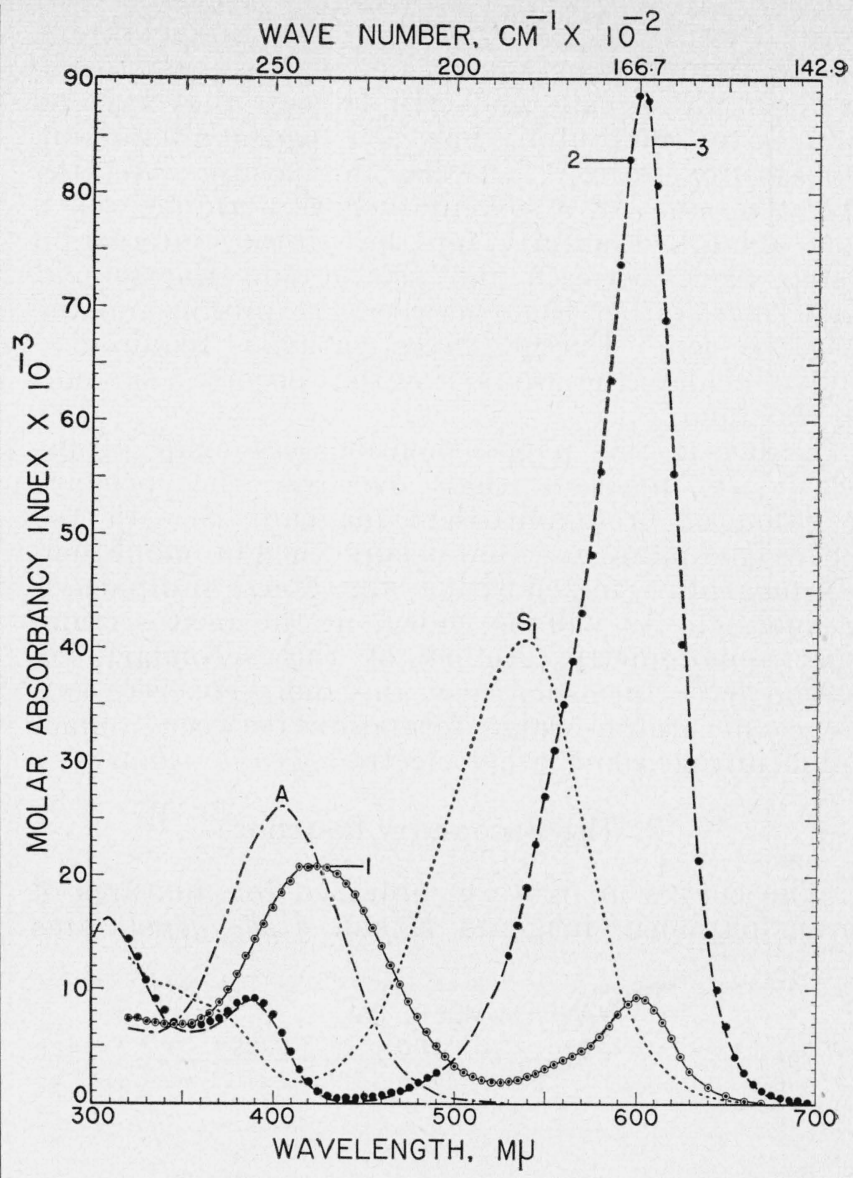

Figure 9. Effect of ethanol on molar absorbancy.

$\mathrm{A}, 2.5 \times 10^{-5}-\mathrm{M}$ bromophthalein magenta $\mathrm{E}$ in benzene; $1,2.5 \times 10^{-5}-\mathrm{M}$ BPM-E in ethanol; $S_{1}, 2.5 \times 10^{-5}-M$ BPM-E with 50 molar equivalents of diphenylguanidine in benzene; $2,2.5 \times 10^{-5}-\mathrm{M}$ BPM-E with 50 molar equivalents of diphenylguanidine in solvent 96 percent ethanol-4 percent benzene by volume; 3 , tetraethylammonium salt of BPM-E in ethanol.

bromophthalein magenta E) was negligible, and $[B]$ was essentially the same as $C_{b}$. The equilibrium constant for the secondary reaction can therefore be formulated as the ratio of the concentrations of $S_{2}$ and $S_{1}$, divided by $C_{b}$, or

$$
K_{2}=\frac{S_{2}}{S_{1} C_{b}}
$$

Computation of $K_{2}$ would be a relatively simple matter if the limiting curve for the secondary salt were the same for all compounds in all solvents. From data at two wavelengths it would be possible to set up simultaneous equations and calculate $S_{2} / S_{1}$ for each solution [41]. However, it would be surprising if the anion, which is responsible for the absorption of light in the visible region, remained unaffected by changes in environment, such as the effective diameter of the cation and the type and amount of polar molecules present. ${ }^{10}$ For this rea-

\footnotetext{
10 See, for example, [40], including the remarks of K. Fajans.
} 


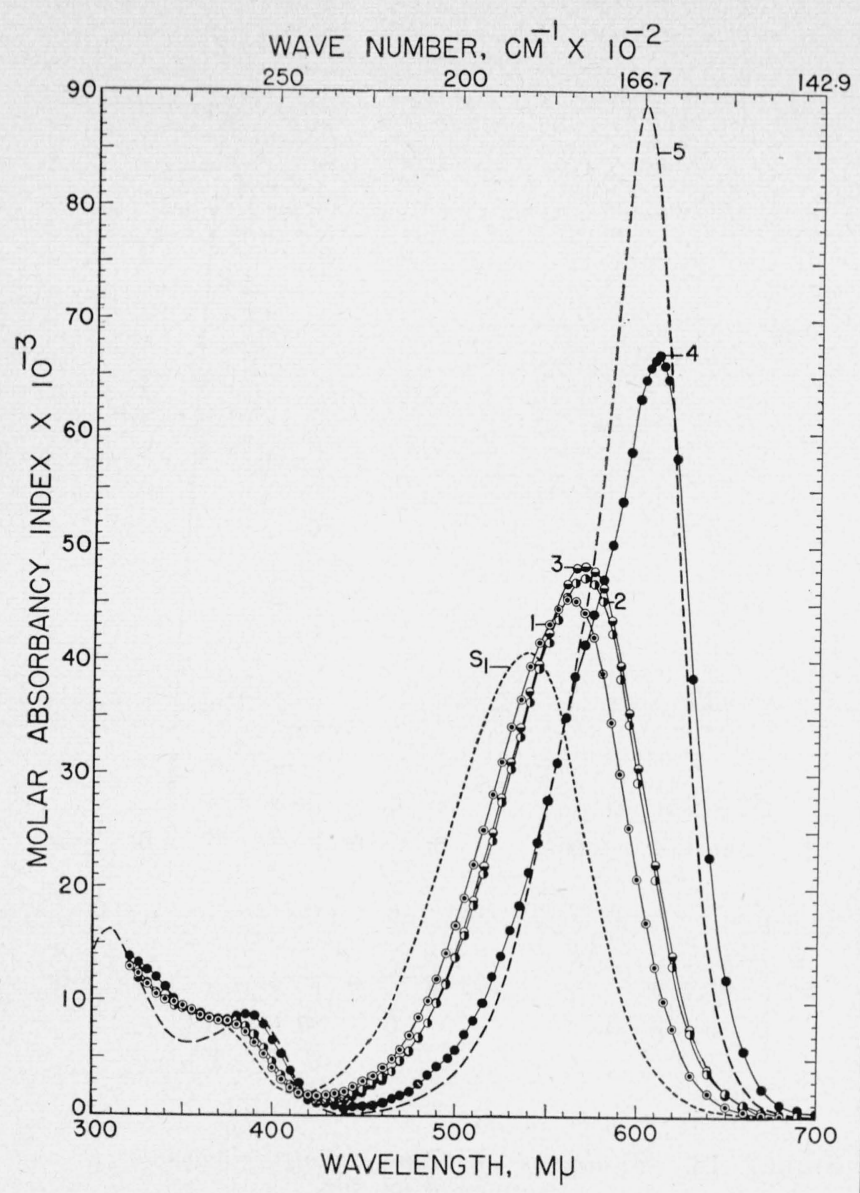

FIGURE 10. Effect of replacing benzene by pyridrne on the molar absorbancy of a solution of bromophthalein magenta $E$ and diphenylguanıdıne.

$S_{1}, 2.5 \times 10^{-5}-M$ BPM-E and 45 molar equivalents of diphenylguanidine in benzene; $1,2.5 \times 10^{-5}-M$ BPM-E and 50 molar equivalents of diphenylguanidine, 15 percent by volume of pyridine; 2 , same as 1 but 30 percent of pyridine; 3 , sam as 2 but 500 molar equivalents of diphenylguanidine; $4,5.0 \times 10^{-4}-M$ BPM-E 120 molar equivalents of diphenylguanidine, 80 percent of pyridine; 5 , tetraethyl ammonium salt of BPM-E in ethanol.

son, it is desirable to avoid high concentrations of polar molecules in the spectrophotometric determination of $K_{2}$. On the other hand, the concentrations must be great enough for precise measurement of $\left[S_{1}\right],\left[S_{2}\right]$, and $[B]$. One may therefore expect that some ranges of concentration will prove more favorable than others for the determination of $K_{2}$.

The complete molar absorbancy curves for two of the solutions used in estimating $K_{2}$ for bromophthalein magenta $\mathrm{E}$ plus diphenvlguanidine in benzene are shown in figure 11; curve 1 is for the mixture with $0.02-M$ diphenylguanidine, and curve 2 is for the mixture with $0.04-M$ diphen ylguanidine. The other eight curves, which showed the same isosbestic points near 370,420 , and $550 \mathrm{~m} \mu$, were omitted from the figure to avoid crowding of the curves.

The data obtained at $600 \mathrm{~m} \mu$ were used in the calculation of $K_{2}$. Our accepted value for the absorbancy for $S_{1}$ at $600 \mathrm{~m} \mu$ is 0.0857 . The limiting value, $z$, for $S_{2}$ at $600 \mathrm{~m} \mu$ was found by trial and error to

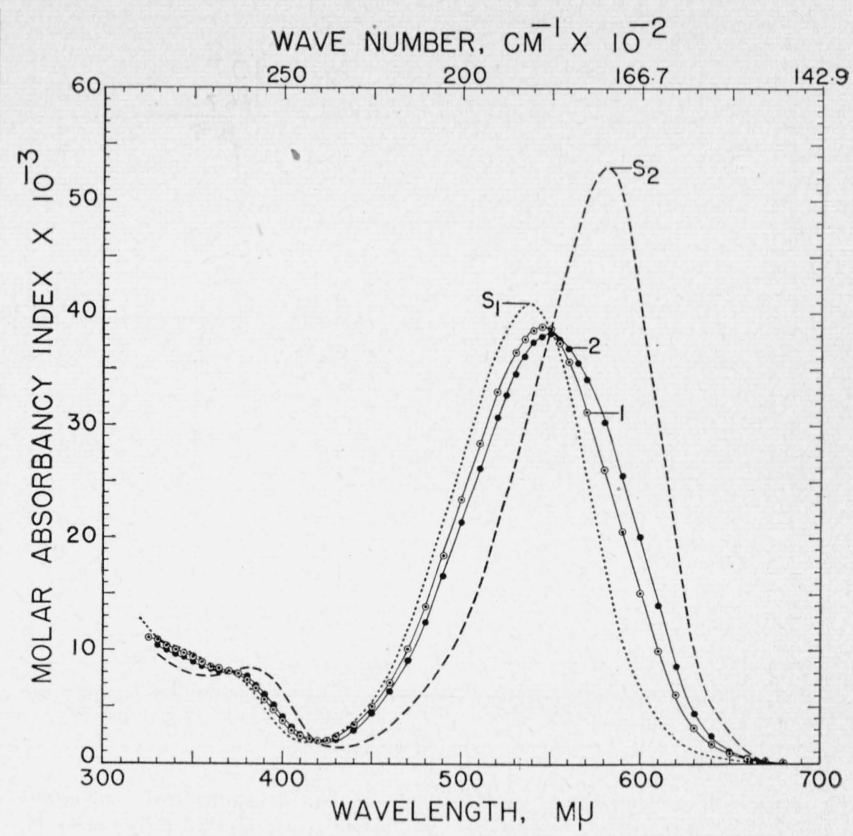

FIGURE 11. Effect of an excess of diphenylguanidine on the molar absorbancy of the primary salt of bromophthalein magenta $E$ and diphenylguanidine in benzene.

$S_{1}, 2.5 \times 10^{-5}-M$ BPM-E with 45 molar equivalents of diphenylguanidine; 1 and $2,2.5 \times 10^{-5}-M$ BPM-E with $0.02-\mathrm{M}$ and $0.04-M$ diphenylguanidine, respectively; $S^{2}$, calculated curve for the secondary salt.

be 0.510 . Then $S_{2} / S_{1}=\left(A_{s}-0.0857\right) /\left(0.510-A_{s}\right)$. The experimental absorbancies at $600 \mathrm{~m} \mu$ and the calculated values are given in table 6 . The values derived for $K_{2}$ ranged from 15.2 to 15.8 , with the average value, 15.5 . (The value obtained for $0.03-M$ diphenylguanidine seemed to be out of line and was omitted in the computation of the average.)

TARLE 6. Experimental data and association constant for the secondary reaction of bromophthalein magenta $E$ with diphenylguanidine in benzene

\begin{tabular}{|c|c|c|c|c|c|c|}
\hline$C_{b}^{\mathrm{a}}$ & $A_{\mathrm{s}}^{\mathrm{b}}$ & $\Delta A_{s}^{\mathrm{e}}$ & $z-A_{8}^{\mathrm{d}}$ & $-\log \left(S_{2} / S_{1}\right)$ & $-\log C_{b}$ & $K_{2}^{\ominus}$ \\
\hline $\begin{array}{r}0 \\
0 \\
115 \\
018 \\
020 \\
025 \\
.025 \\
.030 \\
.035 \\
.036 \\
038 \\
.040\end{array}$ & $\begin{array}{r}0 .{ }^{\triangleleft} 22 \\
.1670 \\
.1786 \\
.1864 \\
.2036 \\
.2168 \\
.2355 \\
.2358 \\
.2425 \\
.2472\end{array}$ & $\begin{array}{r}0.0565 \\
.0813 \\
.0929 \\
.1007 \\
.1179 \\
.1311 \\
.1498 \\
.1501 \\
.1568 \\
.1615\end{array}$ & $\begin{array}{l}0.3678 \\
.3430 \\
.3314 \\
.3236 \\
.3064 \\
.2932 \\
.2745 \\
.2742 \\
.2675 \\
.2628\end{array}$ & $\begin{array}{r}0.814 \\
.625 \\
.552 \\
.507 \\
.415 \\
.350 \\
.263 \\
.262 \\
.232 \\
.212\end{array}$ & $\begin{array}{l}2.000 \\
1.824 \\
1.745 \\
1.699 \\
1.602 \\
1.523 \\
1.456 \\
1.444 \\
1.420 \\
1.398\end{array}$ & $\begin{array}{r}15.4 \\
15.8 \\
15.6 \\
15.6 \\
15.4 \\
* 14.9 \\
15.6 \\
15.2 \\
15.4 \\
15.4\end{array}$ \\
\hline \multicolumn{6}{|c|}{ - } & t 15.5 \\
\hline
\end{tabular}

a Initial concentration of diphenylguanidine in moles per liter of solution. $C$ (initial concentration of bromophthalein magenta $\mathrm{E}$ ) $=2.5 \times 10^{-5} \mathrm{M} /$ liter. Cell length $=5 \mathrm{~mm}$

b Experimental values at $600 \mathrm{~m} \mu$. $600 \mathrm{~m} \mu$ when $2.5 \times 10^{-5} M$ in 5 - $\mathrm{mm}$ cell.

$f$ the assumed limiting value found by trial and error for the secondary salt

$\left(S_{2}\right)$ at $600 \mathrm{~m} \mu,=0.510: \Delta A_{s} /\left(z-A_{s}\right)=S_{2} / S_{1}$.

- $K_{2}=S_{2} /\left(S_{1} \cdot C_{b}\right)$. average.

Graphical evaluation of the equilibrium constant is presented in figure 12 , line $\mathrm{I}$. The experimental 


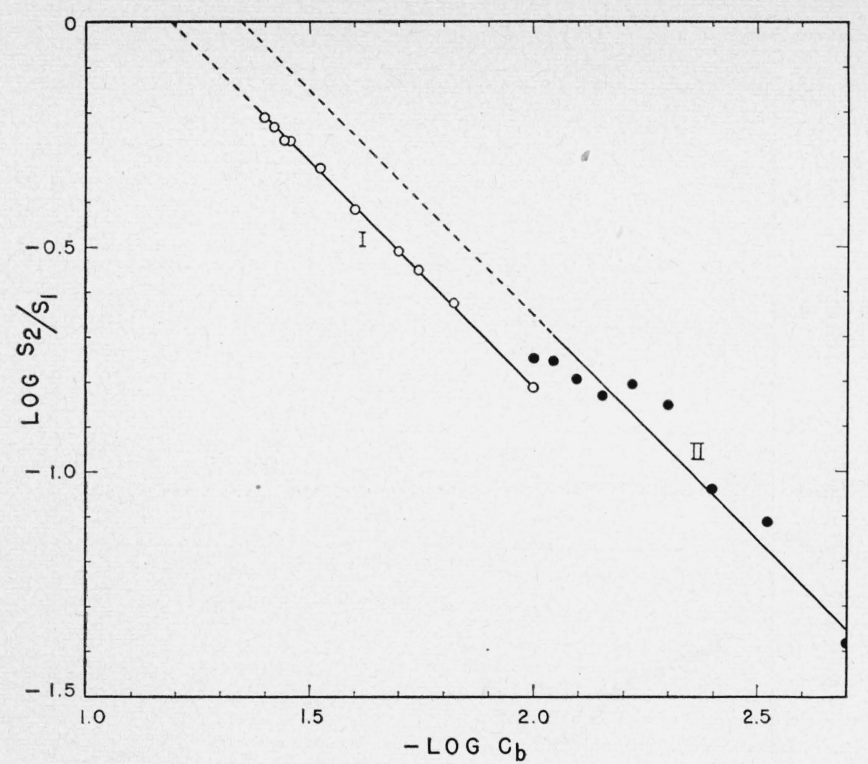

FIgure 12. Graphical evaluation of the association constant for the secondary reaction of bromophthalein magenta $E$, $2.5 \times 10^{-5}-M$ in benzene, with $I$, diphenylguanidine and $I I$, triphenylguanidine; 5-mm cells.

points (open circles) fall on or very close to a line of slope -1 ; this line was drawn so that its intercept on the $x$-axis for $\log S_{2} / S_{1}=0$ is $1.19(\log 15.5)$. The validity of the equation assumed for the secondary reaction is very strongly supported by the close agreement of the values for $K_{2}$ and by the almost perfect coincidence of the plotted points in figure 12 with the theoretical curve, line I.

From the data in table 6 , the curve for $S_{1}$, and the estimated value $(0.510)$ of $S_{2}$ at $600 \mathrm{~m} \mu$, the limiting curve for the secondary reaction of bromophthalein magenta $\mathrm{E}$ with diphenylguanidine was calculated (fig. 11, curve $S_{2}$ ). The general shape of this curve is similar to curve 4 in figures 6 and 7 , curve 7 in figure 8, curves 2 and 3 in figure 9 , and curve 4 in figure 10 . The method of computation was as follows: The increment (or decrement) in absorbancy due to the complete conversion of $2.5 \times 10^{-5}-M S_{1}$ to $2.5 \times 10^{-5}-M S_{2}$ is $0.5100-0.0857$ at $600 m \mu$. At other wavelengths, $A_{s}\left(S_{2}\right)-A_{s}\left(S_{1}\right)$ is unknown, but the ratio $\left[A_{s}\left(S_{2}\right)-A_{s}\left(S_{1}\right)\right] /\left[A_{s}\right.$ (mixture) $\left.-A_{s}\left(S_{1}\right)\right]$ should be the same for all wavelengths, and $A_{s}$ (mixture)$A_{s}\left(S_{1}\right)$ is known for each of the solutions concerned over the wavelength region in question. The increments or decrements were calculated for each of the solutions (except the one containing $0.03-M$ diphenylguanidine), and the average increment or decrement was added to curve $S_{1}$ to give curve $S_{2}$.

Curve $S_{2}$ shows a maximum near $580 \mathrm{~m} \mu$, not near $600 \mathrm{~m} \mu$, although in figure 6 two of the curves for mixtures of BPM-E and diphenylguanidine (curves 3 and 4) show a maximum near $600 \mathrm{~m} \mu$. The two mixtures that gave these curves obviously contained a much larger concentration of $S_{2}$ than the solutions that gave curves 1 and 2 in figure 11 , and it seems possible that at high concentrations the salt is ap-
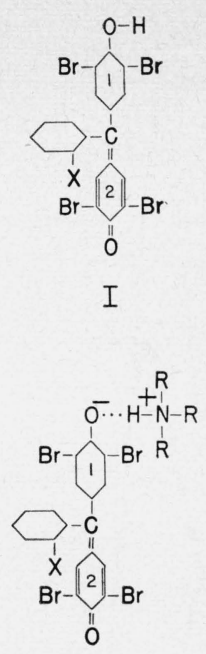

III

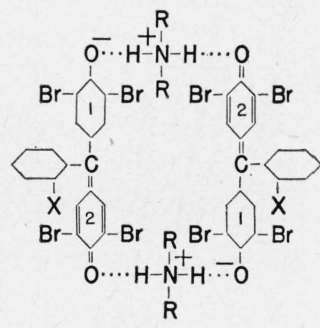

Z

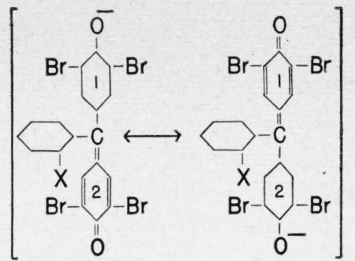

II
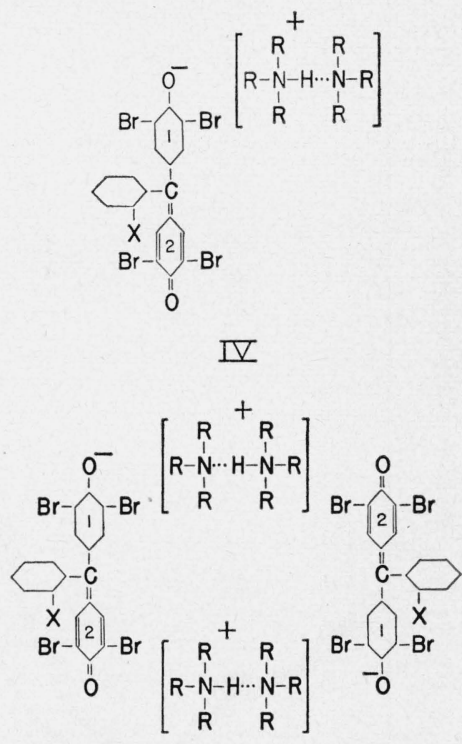

ZI
FIGURE 13. Structures of bromophthalein magenta $E$ and various of its salts.

I, Bromophthalein magenta $\mathrm{E} ; \mathrm{X}=\mathrm{COOC}_{2} \mathrm{H}_{5} ; \mathrm{II}$, Anion of bromophthalein magenta $E$, showing the two structures that contribute chiefly to the iesonance; III, Primary salt of bromophthalein magenta E with a tertiary amine; IV, Secondary salt of bromophthalein magenta $\mathrm{E}$ with a tertiary amine (monomeric structure); $V$, Salt of bromophthalein magenta $\mathrm{E}$ with a secondary amine (dimeric structure); VI, Secondary salt of bromophthalein magenta $\mathrm{E}$ with a tertiary amine (dimeric structure).

preciably dimerized. A possible explanation for a shift of the absorption toward longer wavelengths when dimerization occurs can be made with the aid of figure 13. Formula I in figure 13 is for bromophthalein magenta $\mathrm{E}$ itself; in bromophthalein magenta $\mathrm{E}, \mathrm{X}=\mathrm{COOC}_{2} \mathrm{H}_{5}$. The benzene ring marked 2 has a quinoid structure, which accounts for the yellow color of the solutions. Formula II represents the anion and shows the two structures that contribute chiefly to the resonance that causes absorption at lower frequencies (longer wavelengths). If the anion were completely detached from the phenolic hydrogen of structure I, the two structures within the brackets would be exactly equivalent.

Formula III is for a tertiary ammonium salt of bromophthalein magenta $\mathrm{E}$; the phenolic oxygen is partly released from the restraining effect of the proton, but benzene rings 1 and 2 are not fully equivalent and the absorption band is intermediate in position between those produced by structures I and II. This is the primary salt, $S_{1}$, which gives a magenta solution in benzene. In all of the pri- 
mary salts so far investigated, the effect of the cation on the electron system of the anion appears to be the same. Formula IV is for the secondary salt, $S_{2}$; the positive charge on the cation is further removed from the phenolic oxygen, and this explains why absorption occurs at lower frequencies. The location of the positive charge will vary with the structure of the cation, and this will affect the resonance within the anion. It is also possible that a displacement of the electron cloud toward the oxygen of ring 2 will occur if the oxygen is near the positive end of some dipole, resulting in a further shift in the absorption toward lower frequencies.

Formula V was previously suggested [1] to account for the cornflower blue color of secondary ammonium salts of bromophthalein magenta $\mathrm{E}$ in benzene (absorption maximum near $575 \mathrm{~m} \mu){ }^{11}$ The deeper color, as compared with the tertiary ammonium salt, $S_{1}$, is understandable because rings 1 and 2 are more nearly equivalent in formula $\mathrm{V}$ than in formula III. Formula VI suggests how a similar shift in absorbancy to lower frequencies may occur at high concentrations of the secondary salt (formula IV); two adjacent molecules of the salt may become oriented in such a way that rings 1 and 2 are both adjacent to a cation and thus become more nearly equivalent than they are in formula IV. Such association is not purely hypothetical but has a strong experimental foundation in the work of Kraus and coworkers [42]. It is more likely to occur when the ions are symmetrical.

The calculation of $\boldsymbol{K}_{2}$ for the reaction of bromophthalein magenta $\mathrm{E}$ with triphenylguanidine in benzene was calculated from data at $540 \mathrm{~m} \mu$ for nine solutions with the initial composition $2.5 \times$ $10^{-5}-M$ bromoph thalein magenta $\mathrm{E}$ and from $0.002-M$ to $0.01-M$ triphenylguanidine. The calculation was subject to greater error than in the case of diphenylguanidine, because the changes in absorbancy were smaller and the primary and secondary reactions overlapped. The value 525 given for $K_{1}$ in the preceding section was assumed to be correct and, as in the calculations for the secondary reaction of BPM with diphenylguanidine, $[B]$ was assumed to be the same as $C_{b}$. Since $K_{1}=525, S_{1} / A=525 . C_{b}$. Then $f=\left(S_{1} / A\right) /\left[1+\left(S_{1} / A\right)\right]$ gives the fraction of the indicator that would have been present as the primary salt in the equilibrium mixture if none of the primary salt had been transformed to the secondary salt; multiplying $f$ by 0.5100 gives the absorbancy that would have been observed under these conditions. Similarly, if $y$ is the absorbancy at $540 \mathrm{~m} \mu$ for $2.5 \times 10^{-5}-M$ secondary salt, $f . y$ gives the absorbancy that would have been observed if all of the primary salt formed in the solution had been converted to the secondary salt. Then $S_{2} / S_{1}=$

\footnotetext{
11 Note the distinction in the terms "secondary salt" (formula IV) and "secondary ammonium salt" (formula V). A very striking phenomenon occurs when a basic solvent such as ethanol is added in minute increments to the cornflower blue secondary ammonium salt in benzene. The color first changes to magenta and then, upon the addition of a large excess of ethanol, to the blue of tetraalkylammonium salts of bromophthalein magenta E. These effects were described and explained in [1]
}

$\left(0.5100 f-A_{s}\right) /\left(A_{s}-y f\right)$; dividing this ratio by $C_{b}$ gives $K_{2}$. For $y=0.28$, the values of $K_{2}$ range from 18.0 to 28.2 , with the average value 22.5. The data and calculations are presented in table 7 . In table 8 are listed the values for $K_{2}$ that were obtained for other values of $y$; the most reasonable value of $y$ appears to be in the range 0.2 to 0.4 . The value for $K_{2}$ thus seems to be of about the same magnitude as $K_{2}$ for the reaction of bromophthalein magenta $\mathrm{E}$ with diphenylguanidine, but somewhat larger rather than smaller. An attempt was made to compute $K_{2}$ from experimental values of the absorbancy at $600 \mathrm{~m} \mu$, but the values of $K_{2}$ thus obtained showed a trend toward lower values with increasing $C_{b}$ whatever the value assumed for the limiting absorbancy at $600 \mathrm{~m} \mu$, although they were of the same order as those shown in table 8 . The most likely explanation of this effect appears to be a relative increase in the concentration of a dimer of the secondary salt as well as an increase in polarizing effects caused by the free base, as the concentration of the base is made greater. Effects due to these causes would probably be more marked at 600 than at $540 \mathrm{~m} \mu$. Trial calculations using

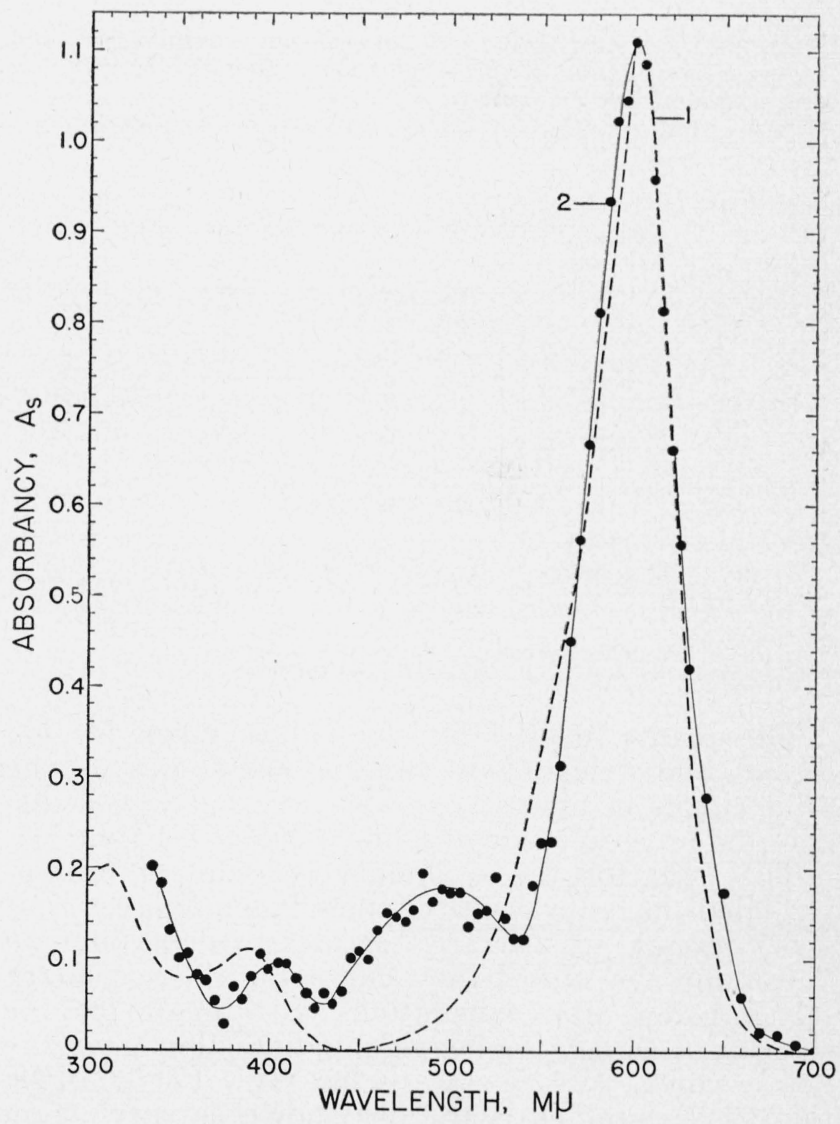

Figure 14. Absorbancy curves of salts of bromophthalein magenta $E$.

1, Tetraethylammonium salt in ethanol; 2, calculated curve for secondary salt with triphenylguanidine in benzene. 
$K_{1}=520,530$, or 540 gave less good agreement of the values for $K_{2}$ at different concentrations of the base, but had little effect on the order of magnitude.

TARLE 7.-Experimental data and association constant for the secondary reaction of bromophthalein magenta $E$ with triphenylguanidine in benzene

\begin{tabular}{|c|c|c|c|c|c|c|c|}
\hline$C_{b^{\mathrm{a}}}$ & $A_{s} \mathrm{~b}$ & $f^{c}$ & $0.5100 f-\boldsymbol{A}_{s}^{\mathrm{d}} \mid$ & $A_{s}-0.28 f^{d}$ & $-\log \left(S_{2} / S_{1}\right)^{\mathrm{d}}$ & $-\log C_{b}$ & $K_{2}{ }^{\mathrm{e}}$ \\
\hline 0.002 & 0. 2565 & $0.5 ! 22$ & 0.0047 & 0.1131 & 1. 381 & 2. 699 & 20.8 \\
\hline .003 & .3019 & .6117 & .0101 & .1306 & 1.112 & 2. 523 & 25.8 \\
\hline .004 & .3325 & 674 & .0130 & .1428 & 1. 041 & 2. 398 & 22.8 \\
\hline .005 & .3487 & .7241 & .0206 & $\begin{array}{r}.1460 \\
\end{array}$ & 0.850 & 2. 301 & 28.2 \\
\hline .006 & .3635 & .7590 & .0236 & .1510 & .806 & 2. 222 & 26.0 \\
\hline .007 & .3778 & .7861 & 0231 & .1577 & .834 & 2. 155 & 20.9 \\
\hline .008 & .3862 & .8077 & .0257 & .1600 & .794 & 2. 097 & 20.1 \\
\hline .009 & .3925 & .8253 & .0284 & .1614 & .754 & 2. 046 & 19.6 \\
\hline .010 & $: 3990$ & .8400 & .0294 & .1638 & .746 & 2. 000 & 18.0 \\
\hline
\end{tabular}

a Initial concentration of triphenylguanidine in moles per liter of solution. $C_{a}$ (initial concentration of bromophthalein magenta $\mathrm{E}$ ) $=2.5 \times 10^{-5} \mathrm{M} /$ liter Cell length $=5 \mathrm{~mm}$.

b Experimental values at $540 \mathrm{~m} \mu$.

c $f=\left(K_{1} \cdot C_{b}\right) /\left[1+\left(K_{1} \cdot C_{b}\right)\right] ; K_{1}=525$.

d $S_{2} / S_{1}=\left(0.5100 \mathrm{f}-A_{s}\right) /\left(A_{s}-y f\right) ; y$ is assumed to be 0.28

e $K_{2}=S_{2} / S_{1} .[B] ;[B]=C_{b}-\left[S_{1}\right]-2\left[S_{2}\right]$, but since $C_{b}$ is very large as compared with $S_{1}$ and $S_{2},[B] \approx C_{b}$.

TABLE 8. Calculated values of association constant for the secondary reaction of bromophthalein magenta $E$ with triphenylguanidine in benzene a

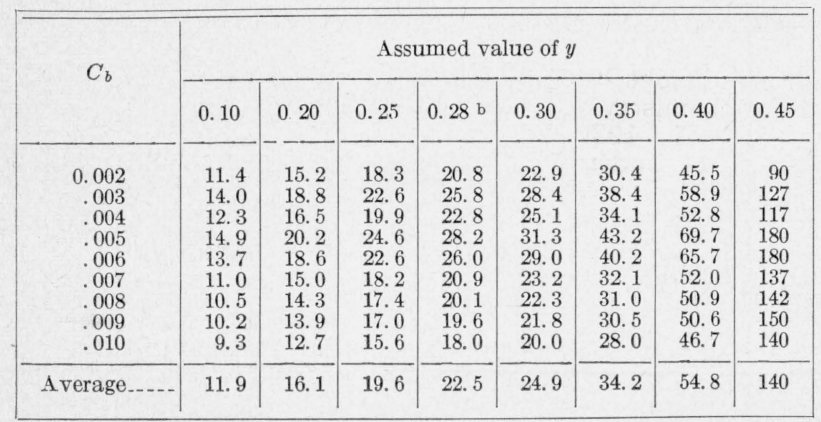

a $K_{2}$ (association constant for the secondary reaction) $=S_{2} / S_{1} \cdot[B]=(0.5100 \mathrm{f}-$ $\left.A_{s}\right) /\left[\left(A_{s}-y f\right) . C_{b}\right] ;[B]=C_{b}-\left[S_{1}\right]-2\left[S_{2}\right] \approx C_{b} ; 0.5100$ is the assumed value for $S_{1}$ and $y$ is the assumed value for $S_{2}$, at $540 \mathrm{~m} \mu$, when $2.5 \times 10^{-5} \mathrm{M}$ in benzene in 5 - $\mathrm{mm}$ absorption cell; $f=K_{1} . C_{b} /\left(1+K_{1} . C_{b}\right)$; the correct value for $K_{1}$ is assumed to be $525 ; A_{s}$ is the measured absorbancy of the solution at $540 \mathrm{~m} \mu$.

b Adopted as probably the best value of $y$ (see the text).

The points located by the values given for log $\left(S_{2} / S_{1}\right)$ and $-\log C_{b}$ in table 7 are shown as the solid circles in figure 12 . They are fairly well distributed on either side of a line of slope - 1 (line II).

The data for the secondary reaction of bromoph thalein magenta $\mathrm{E}$ with triphenylguanidine were not good enough to warrant extensive calculations to determine the absorbancy curve for the secondary salt. A few trial calculations were made for the solution (0.004- $M$ diphenylguanidine) that gave the point which falls closest to line II. For $y=0.28$, the curve obtained is the one shown as curve 2 in figure 14. The resemblance of curve 2 to the absorbancy curve for the tetraethylammonium salt of bromoph thalein magenta $\mathrm{E}$ in ethanol at an equivalent concentration and cell length (curve 1) is so great as to lend further support to the assumptions in regard to the secondary reaction, although we do not believe that it is an accurate representation of the absorbancy curve for the secondary salt of BPM-E with triphenylguanidine. An absorption band near $500 \mathrm{~m} \mu$ was indicated whatever value was used for $y$ within the range considered acceptable. Possibly the complex cation contributes to the absorption at this wavelength.

\section{Further Discussion}

The important theoretical points made in the previous discussion may be summarized as follows:

1. When equivalent amounts of an organic base of the ammonia class and an acid of the BrønstedLowry type react in an "inert" solvent like benzene, a highly polar addition compound is formed. This may be regarded as a salt composed of a pair of ions, held together by Coulombic attraction as well as by interaction between the negative ion and the proton of the hydrogen ion. This addition reaction, termed by the authors "the primary reaction", is analogous to the combination of a base with a Lewis acid. The Brønsted-Lowry acids should thus be regarded as a special class of Lewis acids. The principal arguments on which these statements rest are (a) evidence that ionic dissociation is insignificant under the conditions referred to, (b) quantitative measurements of equilibrium constants for a reaction postulated as $A+B \leftrightarrows S_{1}$, (c) spectrophotometric evidence that the anion is not completely detached from the proton of the cation, and (d) the high dipole moments of the addition products.

2 . When the reaction occurs in the presence of an excess of base, the addition reaction may be succeeded by a "secondary" displacement reaction. An excess of base is essential for appreciable ionization to occur. (The anion displaced by any neutral base may, of course, be regarded as a base.) The primary reaction is generally obscured in a polar solvent such as water. The existence of such reactions has been suspected by a number of investigators, but studies of acid-base reactions in inert solvents were required to establish the reality of the primary reaction and the secondary reaction.

The studies reported in this paper, while helping to clarify the effect of environment on the course of acid-base reactions, suggest other topics for study. Investigations of primary and secondary acid-base reactions should, of course, be extended to systems other than those dealt with in this paper. It would be interesting, for example, to determine the conditions under which the primary and secondary reactions are apt to overlap. One might logically predict that overlapping will not be likely in an inert solvent when the value of $K_{1}$ is large. Steric factors will undoubtedly prove important; in qualitative tests with some aliphatic amines, there was more evidence of the secondary reaction when the amine contained methyl groups than when the smallest substituent was an ethyl group. Such studies obviously have a bearing on the interpretation and 
prediction of the behavior of catalysts as well as of bases of pharmacological importance.

According to the aqueous ionic dissociation constants, triethylamine is a stronger base than diphenylguanidine (see [1], table 2), although the reverse order of basicity is indicated by their relative tendencies to combine with bromophthalein magenta $\mathrm{E}$ or $\mathrm{B}$ in benzene. This would suggest that in water the secondary reaction occurs to a greater extent for triethylamine. In benzene, diphenylguanidine shows the behavior of a very strong base; as shown in the preceding discussion, $K_{1}$ for its association with bromophthalein magenta $\mathrm{E}$ or $\mathrm{B}$ is quite large, and with picric acid (which is presumably a stronger acid than the bromophthalein magentas), it reacts quantitatively at concentrations less than $5 \times 10^{-5} M[43]$. Its capacity for neutralizing acids in inert media and its ability to form stable salts are likely to be greater than would be predicted from the aqueous ionic dissociation constant.

The low reactivity of triphenylguanidine with bromophthalein magenta $\mathrm{E}$, as compared with its moderately great basicity in water ([1], table 2), suggests possible steric hindrance due to the bromine atoms in bromophthalein magenta E. The sulfonephthalein indicators analogous to bromophthalein magenta E-bromophenol blue, chlorophenol blue, and iodophenol blue show the same $\mathrm{pH}$ range in water (see [44], table 1), but differentiating effects might well be found in the reaction of bromophthalein magenta E, chlorophthalein magenta E, and iodophthalein magenta $\mathrm{E}$ with bases in solvents like benzene. So far, the latter two indicators are not available for such studies.

In recent studies of the effect of the basicity of the accelerator in the vulcanization of rubber, Kratz, Young, and Katz found that "within a closely related series of accelerators, the sulfur combined in a given time at a given temperature is a linear function of the logarithm of the basic dissociation constant of the accelerator employed" [45]. Thus, monophenyl-, diphenyl-, and triphenylguanidine show decreasing accelerating power in the order named. Our studies indicate that an extension of this generalization to bases not closely related would be liable to prove fallacious.

\section{References}

[1] M. M. Davis and P. J. Schuhmann, J. Research NBS 39, 221 (1947) RP1825.

[2] J. N. Brønsted, Rec. trav. chim. 42, 718 (1923).

[3] T. M. Lowry, Chemistry \& Industry 42, 43 (1923).

[4] T. M. Lowry, Trans. Faraday Soc. 20, 13 (1924).

[5] J. N. Brønsted, Z. angew. Chem. 43, 229 (1930).

[6] G. N. Lewis, Valence and the structure of atoms and molecules (Chemical Catalog Co., New York, N. Y., 1923).

[7] G. N. Lewis, J. Franklin Inst. 226, 293 (1938).

[8] W. F. Luder and S. Zuffanti, The electronic theory of acids and bases (John Wiley \& Sons, Inc., New York, N. Y., 1946).
[9] G. N. Lewis, Science 30, 1 (1909); also Z. phys. Chem. 70, $212(1909)$.

[10] V. K. LaMer and H. C. Downes, J. Am. Chem. Soc. 53, 888 (1931); 55, 1840 (1933).

[11] V. K. LaMer and H. C. Downes, Chem. Rev. 13, 47 (1933).

[12] J. N. Brønsted, Ber. deut. chem. Ges. 61, 2049 (1928).

[13] I. M. Kolthoff, Chem. Eng. News 28, 2882 (1950).

[14] R. Nietzki and E. Burckhardt, Ber. deut. chem. Ges. 30, 175 (1897).

[15] S. J. O'Brien, C. L. Kenny, and R. A. Zuercher, J. Am. Chem. Soc. 61, 2504 (1939).

[16] L. A. K. Staveley, J. H. E. Jeffes, and J. A. E. Moy, Trans. Faraday Soc. 39, 5 (1943).

[17] H. A. Benesi and J. H. Hildebrand, J. Am. Chem. Soc. 71, 2703 (1949).

[18] R. S. Mulliken, J. Am. Chem. Soc. 7\%, 600 (1950).

[19] N. S. Rao and S. K. K. Jatkar, Quart. J. Indian Inst. Sci. 6, 1 (1943)

[20] M. M. Davis and E. A. MeDonald, J. Research NBS 42, 595 (1949) RP1997.

[21] H. Lund and J. Bjerrum, Ber. deut. chem. Ges. 64, 210 (1931).

[22] L. Hunter and J. A. Marriott, J. Chem. Soc. (London) 777 (1941).

[23] M. M. Davis, J. Am. Chem. Soc. 71, 3544 (1949).

[24] J. A. Moede and C. Curran, J. Am. Chem. Soc. 71, 852 (1949).

[25] A. A. Maryott, J. Research NBS 41, 7 (1948) RP1897.

[26] M. A. Elliott and R. M. Fuoss, J. Am. Chem. Soc. 61, 294 (1939).

[27] R. M. Fuoss, D. Edelson, and B. L. Spinrad, J. Am. Chem. Soc. 7\%, $327(1950)$.

[28] C. R. Witschonke and C. A. Kraus, J. Am. Chem. Soc. 69, 2472 (1947).

[29] R. M. Fuoss and C. A. Kraus, J. Am. Chem. Soc. 57, 1 (1935).

[30] P. Walden, Salts, acids, and bases: Electrolytes: Stereochemistry (McGraw-Hill Book Co., Inc., New York, N. Y., 1929).

[31] W. F. Luder and S. Zuffanti, The electronic theory of acids and bases, p. 44 (John Wiley \& Sons, Inc., New York, N. Y., 1946).

[32] C. A. Kraus, Annals of the New York Academy of Sciences 51, 789 (1949).

[33] H. M. Glass and W. M. Madgin, J. Chem. Soc. (London) 193, 1431 (1933); see also H. M. Glass, W. M. Madgin, and F. Hunter, J. Chem. Soc. (London) 260 (1934) and H. M. Glass and W. M. Madgin, J. Chem. Soc. (London) 1292 (1934).

[34] M. L. Huggins, J. Am. Chem. Soc. 58, 694 (1936).

[35] M. L. Huggins, J. Org. Chem. 1, 407 (1936).

[36] T. S. Moore, J. Chem. Soc. (London) 91, 1373, 1379 (1907).

[37] T. S. Moore and T. F. Winmill, J. Chem. Soc. (London) 101, 1635 (1912).

[38] P. Walden and E. J. Birr, Z. phys. Chem. A 160, 327 (1932).

[39] A. F. Trotman-Dickenson, J. Chem. Soc. (London) 1293 (1949).

[40] C. A. Kraus, J. Phys. Chem. 43, 231 (1939).

[41] M. G. Mellon, editor, Analytical absorption spectroscopy; chapter 7, E. I. Stearns, Applications of ultraviolet and visual spectrophotometric data (John Wiley \& Sons, Inc., New York, N. Y., 1950).

[42] C. A. Kraus, Trans. Electrochem. Soc. 66, 179 (1934).

[43] M. M. Davis and E. A. MeDonald, unpublished spectrophotometric data.

[44] M. M. Davis, P. J. Schuhmann, and M. E. Lovelace, J. Research NBS 41, 27 (1948) RP1900.

[455] G. D. Kratz, H. H. Young, Jr., and I. Katz, Ind. Eng. Chem. 41, 399 (1949).

Washington, December 19, 1950. 
